Limits to arbitrage during the crisis: funding liquidity constraints and covered interest parity

Tommaso Mancini Griffoli and Angelo Ranaldo

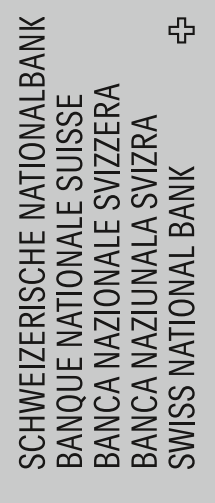


The views expressed in this paper are those of the author(s) and do not necessarily represent those of the Swiss National Bank. Working Papers describe research in progress. Their aim is to elicit comments and to further debate.

\section{Copyright $\odot$}

The Swiss National Bank (SNB) respects all third-party rights, in particular rights relating to works protected by copyright (information or data, wordings and depictions, to the extent that these are of an individual character). SNB publications containing a reference to a copyright ( $\odot$ Swiss National Bank/SNB, Zurich/year, or similar) may, under copyright law, only be used (reproduced, used via the internet, etc.) for non-commercial purposes and provided that the source is mentioned. Their use for commercial purposes is only permitted with the prior express consent of the SNB.

General information and data published without reference to a copyright may be used without mentioning the source.

To the extent that the information and data clearly derive from outside sources, the users of such information and data are obliged to respect any existing copyrights and to obtain the right of use from the relevant outside source themselves.

\section{Limitation of liability}

The SNB accepts no responsibility for any information it provides. Under no circumstances will it accept any liability for losses or damage which may result from the use of such information. This limitation of liability applies, in particular, to the topicality, accuracy, validity and availability of the information.

ISSN 1660-7716 (printed version)

ISSN 1660-7724 (online version)

๑ 2010 by Swiss National Bank, Börsenstrasse 15, P.0. Box, CH-8022 Zurich 


\title{
Limits to arbitrage during the crisis: funding liquidity constraints and covered interest parity*
}

\author{
Tommaso Mancini Griffoli and Angelo Ranaldo ${ }^{\dagger \ddagger}$ \\ Swiss National Bank
}

June 2010

\begin{abstract}
Arbitrage normally ensures that covered interest parity (CIP) holds. Until recently, excess profits, if any, were documented to last merely seconds and reach a few pips. Instead, this paper finds that following the Lehman bankruptcy, these were large, persisted for months and involved strategies short in dollars. Profits are estimated by specifying the arbitrage strategy as a speculator would actually implement it, considering both unsecured and secured funding. Either way, it seems that dollar funding constraints kept traders from arbitraging away excess profits. The claim finds support in an empirical analysis drawing on several novel high frequency datasets of synchronous quotes across securities, including transaction costs.
\end{abstract}

JEL classification: F31, G01, G14

Keywords: arbitrage limits, covered interest parity, funding liquidity, financial crisis

*A previous version of this paper has circulated under the title "Deviations from covered interest parity during the crisis: a story of funding liquidity constraints"

†tommaso.mancini@snb.ch, angelo.ranaldo@snb.ch

$\ddagger$ The views expressed in this paper are those of the authors and do not necessarily reflect those of the Swiss National Bank. Many thanks to Jonathan Berk, Markus Brunnermeier, Colin Bermingham, Alain Chaboud, Mark Dearlove, Ray Fair, Charles Goodhart, Alfred Günter, Rainer Häberle, Harald Hau, Terrence Hendershott, Michael King, Adam Law, Antonio Mele, Michael Melvin, Lubos Pastor, Lasse Pedersen, Ronnie Sadka, Hyun Song Shin, Paul Söderlind, Giorgio Valente, Dimitri Vayanos and an anonymous referee (SNB working papers) for very helpful comments. Thanks also to SNB traders and asset managers Roman Bauman, Sebastien Kraenzlin, Christoph Meyer, and Martin Schlegel for insightful discussions, as well as to participants at the 2009 Gerzensee symposium on finance and the 2009 SNB-BOP joint research conference for stimulating comments. Finally, we kindly acknowledge Tullet Prebon, ICAP and Eurex, especially Rene Winkler, for their kindness in answering our questions and efficiency in providing us with data. 
A system's dynamics often stand out more clearly when observed under some strain. Connections too faint to be noticed are amplified and relations too complex to be grasped are untangled. In this sense, the recent financial crisis has opened new fields of research and turned attention to questions formerly overlooked. Such is the case for the covered interest parity condition (CIP) which, until the Lehman bankruptcy, was assumed to hold without reservations and used widely to price forward exchange rate contracts. The CIP condition was perceived to be solidly anchored in riskless arbitrage, a notion essential and ubiquitous in finance for asset pricing.

But even such fundamental conditions have their limits. Keynes, already in 1923, expressed the intuition that the CIP condition may be violated if "speculation is exceptionally active and is all one way. It must be remembered that the floating capital normally available... for the purpose of taking advantage of moderate arbitrage. . . is by no means unlimited in amount" and thus excess profits, when they arise, persist until "fresh capital [is drawn] into the arbitrage business" (Keynes, 1923). Today, in our modern, highly efficient markets, it seems that Keynes' intuition still applies: in the months following the Lehman bankruptcy, the CIP condition broke down and arbitrage opportunities were left unexploited, a situation exacerbated first and foremost by the lack of funding liquidity in dollars.

This paper has two goals: first of documenting CIP deviations during the crisis and second of explaining them. Documentation begins with an effort to specify the arbitrage strategy as a speculator would actually implement it. Two approaches are considered. The first, closer to the operations of a bank's proprietary trading desk (prop desk), involves rolling over overnight unsecured money market positions across currencies, and hedging interest rate risk using overnight index swap (OIS) contracts. The second, more symptomatic of a hedge fund, suggests borrowing and lending against collateral, using repo contracts. We call the first unsecured arbitrage and the second secured. Data, relative to each strategy, come from novel datasets offering multiple daily snapshots of interbank quotes, synchronous across securities and, in most cases, inclusive of transaction costs. Deviations from the CIP condition of up to 360 bps annualized appear incontestably after the Lehman bankruptcy, and last until year-end. They are somewhat smaller and less persistent, though, than those found in earlier studies which use more coarse data. Furthermore, deviations from CIP are (i) currency specific and (ii) directional, in the sense that they appear on trades involving the US dollar and, specifically, in which the dollar is the funding currency.

In short, insufficient arbitrage flows failed to exert the necessary pressure on the forward forex market, leaving the forward rate "mis-priced" according to CIP. Specifically, during the post Lehman period, the dollar was too cheap 
on the forward market, as compared to the rate suggested by the CIP condition. While those traders who did have access to dollar funding probably made hefty profits at very low risk from CIP arbitrage at the height of the crisis, to most others this opportunity merely remained out of reach; thus, to speak of excess returns from CIP arbitrage means that potential profits were left unexploited.

But why did arbitrage break down? That is the focus of the second part of this paper. Two hypotheses are entertained, one emphasizing risk and the other liquidity factors. The distinction is useful also because secured arbitrage, as opposed to unsecured, removes many of the trading risks and therefore offers a natural experiment to test the importance of risks on excess returns. More generally, this paper's empirical analysis suggests liquidity factors dominate. Dollar funding was rationed due to deleveraging imperatives, prudential hoarding in the face of growing internal funding and liquidity needs, as well as limited capital to pledge in exchange for liquid funds. In this light, the erosion of excess profits and stabilization of the CIP condition at the end of 2008 can be explained by the return of dollar liquidity on money markets, in great part due to the generous central bank swap lines established in the wake of the Lehman bankruptcy.

Several studies precede this paper in exploring deviations from CIP, starting with Frenkel and Levich $(1975,1977)$. More recently, several papers have focussed on the 2007-2009 financial crisis and have deservedly received significant attention in both academic and policy circles. The studies include Baba, Packer, and Nagano (2008), later expanded into Baba and Packer (2008, 2009), as well as Coffey, Hrung, Nguyen, and Sarkar (2009), Genberg, Hui, Wong, and Chung (2009) and Jones (2009). Yet, all approach the question of CIP deviations using Libor rates across currencies as a measure of funding costs, to be compared to the forward premium (the difference between the forward and spot exchange rates). This raises four issues.

First, these data are somewhat different than those that a trader would have faced. Libor rates are an ask price, are indicative and perhaps biased due to mis-representation or strategic signaling. In fact, the accuracy of Libor rates during the crisis became an important subject of controversy, as pointed out by McAndrews (2009).

Second, Libor rates are only available at 11 am London time, thus often not matching the time stamp of the foreign exchange quotes used. This issue is bound to have been especially important during the crisis given the extreme market volatility. Jones (2009) attempts to circumvent the problem by using data on interest rate futures, but admits these may have been relatively illiquid and their inflexible nature would have limited their use in arbitrage.

Third, Libor rates used in the above mentioned studies are of relatively 
long maturities: 1 or 3 months. But, as documented by Taylor and Williams (2009), their respective markets became exceptionally illiquid during the crisis. This suggests traders would have turned to other markets or used much shorter maturity instruments to undertake arbitrage strategies. That is indeed the approach taken in this paper.

Finally, and importantly, transaction costs grew considerably during the crisis, as will be shown later, a factor overlooked in the above mentioned literature but important to replicate traders' actual profit opportunities.

The papers that have used finer data are few and pre-date the crisis. The four that stand out are Taylor (1989), Rhee and Chang (1992), Akram, Rime, and Sarno (2008) and Fong, Valente, and Fung (2009, forthcoming). These papers all use high frequency data, synchronous among the various markets under study, and inclusive of bid-ask spreads as a measure of transaction costs. In most cases, though, the datasets typically span just a few months.

This paper also provides empirical grounding to the wider, currently very dynamic, and mostly theoretical literature on market freezes, in which liquidity issues often play a central role in explaining limits to arbitrage. But instead of offering a blanket review here, relevant works are mentioned throughout this paper, in support of hypotheses raised to explain CIP arbitrage profits.

The rest of this paper is organized as follows. Section 1 discusses how CIP arbitrage is implemented in practice and derives corresponding specifications of payoffs. Section 2 reviews the relevant data and offers estimations of excess profits from arbitrage. Section 3 focusses on explaining these. It begins by laying out possible hypotheses and tests these in a subsequent empirical analysis. Note that in this paper the following terms are used interchangeably: excess returns or profits from CIP arbitrage, CIP deviations and breakdown of CIP.

\section{The structure of CIP arbitrage}

\subsection{Two types of traders}

Basic CIP arbitrage entails borrowing in one currency and lending in another to take advantage of the interest rate differential while avoiding exchange rate risk. The trade is usually described as borrowing in currency $k$ at an interest cost of $r_{k, t}$, exchanging the sum to currency $j$ using the spot forex market, lending the proceeds in currency $j$ at a rate $r_{j, t}$, and eventually exchanging the principal and accrued interest back to currency $k$ to reimburse the original loan with interest. The latter transaction is undertaken using a forward forex 
contract thereby eliminating exchange rate risk.

Gains from CIP arbitrage are often expressed as,

$$
z_{1, t}=\frac{F_{t \cdots T}}{S_{t}}\left(1+r_{j, t}\right)-\left(1+r_{k, t}\right)
$$

where the spot exchange rate $S_{t}$ is expressed as the price in currency $k$ of one unit of currency $j$. The same is true of the forward exchange rate, $F_{t \cdots T}$, where the subscript captures the time the contract is written and its maturity.

Because all variables are known at time $t$, as emphasized by the shared subscripts, textbooks point out that CIP arbitrage is riskless and should therefore yield zero profits. When re-arranged with $z_{1, t}=0$, the above equation is often referred to as the "CIP no arbitrage condition", or just the "CIP condition" for short.

But the above characterization of the CIP condition leaves out important details mostly related to implementation - central, of course, to this paper. What instruments are used to borrow and lend? What transactions are undertaken? Are there, contrarily to the textbook simplification, hidden costs and risks in a CIP arbitrage trade? What is the term over which CIP arbitrage should hold? ${ }^{1}$

There are two general types of traders involved in CIP arbitrage: hedge funds and prop desks of large financial institutions (banks). The distinction is the same as that in Brunnermeier and Pedersen (2009). Importantly, each trader typically operates on different funding markets. Hedge funds tend to borrow and lend on secured terms, while banks tend to tap the unsecured interbank market. ${ }^{2}$ Each strategy involves different interest rates and maturities, and has different risk and liquidity implications. This paper considers both. We refer to the first as secured CIP arbitrage and to the second as unsecured. The comprehensive trade is illustrated in figure 1, where the trader stands between lender $\mathrm{L}$ and borrower $\mathrm{B}$, with whom she entertains either unsecured or secured money market transactions. The trader also engages in a spot and a forward transaction with her forex counterparty. All in all, the figure highlights the four transactions involved in CIP arbitrage. The following two sections work out the details and payoffs of the unsecured and secured arbitrage strategies.

\footnotetext{
${ }^{1}$ Note, in passing, that if there were risks in a CIP trade, it could not, strictly speaking, be called arbitrage. Yet, we continue to use the term as is commonly done in the literature.

${ }^{2}$ Note that hybrid strategies are also possible: borrowing on secured terms and lending on unsecured terms, but these are not considered in this paper for expositional clarity, and because resulting excess profits are a simple positive transformation of the first two cases.
} 


\subsection{Unsecured CIP arbitrage}

Unsecured CIP arbitrage involves rolling over overnight unsecured money market positions. The reason for using the overnight market is to benefit from greater liquidity and less counterparty default and term risk. The strategy is therefore cheaper on the borrowing side and less risky on the lending side than using term loans. The expected (ex-ante) payoff from such a strategy is given by,

$$
z_{2, t}=\frac{F_{t \cdots T}^{B}}{S_{t}^{A}}\left(1+r_{j, t \cdots T}^{C, B}\right)-\left(1+r_{k, t \cdots T}^{C, A}\right)
$$

where as earlier the subscript $t \cdots T$ indicates the time of purchase and maturity of a security, respectively, and $r_{j, t \cdots T}^{C}$ are the cumulative interest rates in currency $j$ given by rolling over overnight loans. More explicitly, these are given by,

$$
\begin{aligned}
1+r_{k, t \cdots T}^{C, A} & =\mathbb{E}_{t}\left[\prod_{s=t}^{T-1}\left(1+r_{k, s \cdots s+1}^{A}\right)\right] \\
1+r_{j, t \cdots T}^{C, B} & =\mathbb{E}_{t}\left[\prod_{s=t}^{T-1}\left(1+r_{j, s \cdots s+1}^{B}\right)\right]
\end{aligned}
$$

where $r$ without a superscript captures overnight lending rates.

The last thing to note in the above equations are the $B$ and $A$ superscripts. These denote bid and ask quotes, respectively, to incorporate transaction costs related to arbitrage. We assume, as is standard, that the trader pays the ask quotes on what she acquires and the bid quotes on what she sells. ${ }^{3}$

An immediate drawback from such a strategy is interest rate risk. At time $t$, the above merely reflects the expectation of the future path of overnight interest rates, from which, of course, actual rates may vary substantially. Traders typically hedge this risk by engaging in appropriate interest rate swaps, in this case using overnight index swaps, or OIS.

An OIS is a fixed/ floating interest rate swap with the floating leg tied to the effective unsecured interbank overnight rate, such as the Federal Funds rate in the US, the EONIA in the euroarea, or the SONIA in the UK. A trader borrowing cash overnight in currency $k$ will want to hold an OIS contract

\footnotetext{
${ }^{3}$ The bid and ask quotes on the forex market perhaps deserve an additional explanation: when a trader buys currency $j$ while selling currency $k$ in the spot market, she pays the ask price for the $j k$ exchange rate, where, by convention, the exchange rate is the price of the currency cited first in units of that cited second (such as for EURUSD, where the exchange rate is the price in dollars of one euro).
} 
requiring her to pay a fixed rate and paying her a flexible rate equal, in fact, to the rate she pays on her short cash position. Intuitively, the flexible interest rate streams cancel each other out, leaving the trader to pay a fixed rate known at time $t$. More explicitly, the OIS rate in currency $k, r_{k, t \cdots T}^{O}$, is given by,

$$
1+r_{k, t \cdots T}^{O}=1+r_{k, t \cdots T}^{C}=\mathbb{E}_{t}\left[\prod_{s=t}^{T-1}\left(1+r_{k, s \cdots s+1}\right)\right]
$$

where the absence of bid or ask quotes on the right hand side captures the fact that the flexible leg of the OIS is indexed on an effective, or traded, rate.

To summarize, the trader rolls over overnight money market positions, short in currency $k$ and long in currency $j$. She then hedges away interest rate risk with a long position in a currency $k$ OIS contract and a short position in a currency $j$ OIS contract. As a result, the trader's expected payoff from CIP arbitrage is given by,

$$
\begin{aligned}
z_{3, t}= & \frac{F_{t \cdots T}^{B}}{S_{t}^{A}}\left[\left(1+r_{j, t \cdots T}^{C, B}\right)-\left(1+r_{j, t \cdots T}^{C}\right)+\left(1+r_{j, t \cdots T}^{O, B}\right)\right]+ \\
& {\left[\left(1+r_{k, t \cdots T}^{C}\right)-\left(1+r_{k, t \cdots T}^{C, A}\right)-\left(1+r_{k, t \cdots T}^{O, A}\right)\right] }
\end{aligned}
$$

\subsection{Secured CIP arbitrage}

The trader in this situation (hedge fund), pledges capital to obtain a secured loan from lender L. It then turns around and offers funds to borrower B against collateral. In practice, to the extent that foreign currency collateral is accepted, the hedge fund can use at least some of the collateral received from borrower B to pledge to lender L. But we simplify the conceptual framework again for expositional purposes, requiring the hedge fund to have its own capital to pledge in order to borrow cash. Either way, because counterparty default risks disappear, we assume the hedge fund engages in term loans and no longer rolls over overnight positions. The resulting payoff is given by,

$$
z_{4, t}=\frac{F_{t \cdots T}^{B}}{S_{t}^{A}}\left(1+r_{j, t \cdots T}^{R, B}\right)-\left(1+r_{k, t \cdots T}^{R, A}\right)
$$

where the $R$ superscript indicates repo rates. Subtleties and indirect costs associated with the above trades are discussed later in the empirical section. 


\section{Measuring excess profits from CIP arbi- trage}

\subsection{Data for unsecured CIP arbitrage}

Moving from theory to data, we make one simplification. Equation (5) requires data on OIS rates in two currency markets as well as half spreads on future overnight money market rates. But the latter are not know to the trader at time $t$, nor are they available to us. More importantly, these are likely to be very small, especially compared to the size of deviations from CIP that we document later. For estimation purposes we therefore simplify expected payoffs from unsecured CIP arbitrage so that these equal,

$$
z_{3, t}^{\prime}=\frac{F_{t \cdots T}^{B}}{S_{t}^{A}}\left(1+r_{j, \cdots T}^{O, B}\right)-\left(1+r_{k, t \cdots T}^{O, A}\right)
$$

Note that had we not assumed that the trader hedged her interest rate risk, we would have been in a much worse position to estimate ex-ante arbitrage profits. Indeed, as per equation (2), we would have had to know and aggregate traders' expectations of future overnight interest rates. Fortunately, this is precisely what is contained in the OIS rates in the above equation.

To match this payoff, we use data that is (i) synchronous across securities, (ii) representative of participating institutions, and (iii) close to firm quotes. Data were acquired from Tullet Prebon (TP), a leading intermediary in wholesale financial markets facilitating the trading activities of its large client base, including financial institutions, brokers, market makers and hedge funds.

First, data used are perfectly synchronous across the forex and money markets considered, coming from four daily snaps at 9am, 11am, 4pm and $11 \mathrm{pm}$, London time. The first, third and fourth time snaps capture the trading hours of, respectively, the European and Asian, European and US, and US and Asian markets. The second time snap coincides with the Libor fixing.

Second, while all prices are market prices, they are technically indicative. Yet, they are very close to actually traded prices. This is because TP clients emitting quotes often end up trading on the TP platform. Thus, the TP platform is not a venue for marketing purposes. This is especially true for forward contracts for which there are few alternative platforms to trade. It is somewhat less the case for forex spot transactions, where the common alternative is ICAP's Electronic Brokering Services (EBS). A comparison 
suggests TP data is very close to actual traded prices on EBS. ${ }^{4}$

Finally, data cover EURUSD, USDCHF, USDJPY, GBPUSD, as well as a EURCHF, the later serving as a control rate not involving the dollar. In each case, data cover spot rates, and as well as relevant OIS and forward contracts of 1 week as well as 1, 3, 6, 8, 12 and 24 month maturities. In each case, data are for both bid and ask quotes and span from March 2006 to end of April 2009. ${ }^{5}$

\subsection{Data for secured CIP arbitrage}

Data on interbank repo rates are notoriously difficult to obtain. We acquired data on USD interbank repo rates from ICAP whose BrokerTec trading platform accounts for over half the interbank repo market in the US. Data are actual traded prices and cover several daily snaps, although we use data from market opening, at 7.45 am New York time, where trading is most liquid. Furthermore, data are for GC as well as Agency collateral, and cover overnight, one week as well as long term maturities. Liquidity is highest for overnight contracts, although substantial liquidity still exists for one week maturities. We focus on the latter contract so as to replicate arbitrage strategies of some duration, as in the unsecured case. Lastly, and importantly, we use repo rate on GC collateral. Not only are these most liquid, but they are also much more closely comparable to repo rates in other currency markets where similar collateral pools of government bonds are offered. Also, using data from non-GC collateral is misleading as rates often reflect the special nature of specific collateral, making data much more volatile and less representative of a benchmark borrower.

Eurex AG were gracious enough to share their data on EUR interbank repo rates, on the basis of the close working relationship between Eurex and the Swiss National Bank. Again, data are traded prices and stem from Eurex's GC Pooling platform accounting for a very substantial share of interbank repo trading for ECB GC collateral (corresponding to the ECB's definition of GC collateral). Comparable $\mathrm{CHF}$ GC repo rates are from the Swiss National Bank; this is the only repo dataset for which we also have bid and ask quotes. In both cases, data are for overnight as well as one week term contracts. Again, we focus on the latter.

\footnotetext{
${ }^{4}$ Average differences in bid-ask quotes between 2007-2008 were less than 1 pip, differences greater than 2 pips only occurred $5 \%$, without ever surpassing 7 pips.

${ }^{5}$ Forward rates are expressed in "pips" to be divided by $10^{4}$ and added to the spot rate. Note also that OIS rates are annualized and thus needed to be adjusted by a multiplier in order to be consistent with their maturity. The multiplier is $\mu=T / 360$ where $T$ is maturity in days, except for sterling and yen for which the denominator is 365 .
} 
In both the EUR and CHF cases, we have daily trade histories. We therefore pick the trade that is closest to $2 \mathrm{pm}$ London Time, in order to coincide with USD repo data. This unfortunately does not allow us to be perfectly synchronous with the forex market data, although using snaps from 11 am or 4 pm London time barely changes estimated excess returns.

\subsection{Summary of findings}

We begin with excess returns from unsecured arbitrage, covering a richer dataset of currencies, then proceed to secured arbitrage. Figure 2 shows excess returns in percentage points for 1 month arbitrage trades in the "USD group" (EURUSD, USDCHF, USDJPY, GBPUSD), where each trade is labeled according to its corresponding spot position (as explained earlier, a long EURUSD trade involves borrowing in dollars and lending in euros).

In each case, excess profits are very close to zero in the pre-crisis phase, up to August 2007 (often even slightly negative because of transaction costs). Then, profits increase in both level and volatility during the crisis phase, and peak at the time of the Lehman bankruptcy to the very substantial level of 30 bps over one month, or 360 bps on an annualized basis. Thereafter CIP profits remain surprisingly high until year-end (on average 120 bps annualized). The second peak in excess profits can most likely be associated with window dressing typically visible at end of year, where financial firms unwind positions to favor liquid and safe assets on their balance sheets. Since 2009, profits decreased substantially and remained modest, if at all positive, albeit with sustained volatility. As a comparison, Akram, Rime, and Sarno (2008) study CIP deviations from tick-by-tick data in 2004 over various currency pairs. They find that annualized mean returns from CIP arbitrage range from 2 to 15 pips and last between 2 to 16 seconds.

Figure 3, instead, plots excess profits for the reverse of the above trades, where a long spot position becomes short. In each case, profits are negative throughout the sample, especially during the Lehman phase, as expected. The figure is not a perfect mirror image of the first, though, due to the inclusion of bid-ask spreads which change the price of going long or short in any one currency.

The above can be contrasted with excess profits from CIP trades on the EURCHF rate, shown in figure 4. In this case, CIP arbitrage profits are negative throughout the sample, independently of the direction of trade, namely with either short or long spot positions. Volatility did increase during the Lehman phase, but this only made excess profits more negative. At the end of sample, in April 2009, excess profits had returned to normal levels.

Two important takeaways emerge from the above figures. First, excess 
profits are currency specific: they include trades where the dollar is present. Second, excess profits are directional: they emerge when the dollar is being shorted on the spot market. These two elements are key guideposts to formulate and test a hypothesis explaining the breakdown of CIP arbitrage.

Excess returns from secured arbitrage are presented in figures 5 and 6 . Taking a cue from the above findings, results are only presented for arbitrage long in EURUSD and short in USDCHF, over a 1 week term. In both cases, results are compared to the unsecured payoffs over the same term. Note first that excess returns also spike at the time of the Lehman bankruptcy, but for approximately two and one months, respectively, thus less than in the unsecured case. This is primarily a result of the shorter term of arbitrage, a relation that is explored more systematically in the robustness checks to this paper's empirical section. Second, and importantly, excess returns from secured arbitrage are nearly exactly equal to those from unsecured arbitrage. This is especially true for arbitrage in EURUSD, although while a slight gap opens in the case of USDCHF arbitrage, co-movement between unsecured and secured arbitrage profits is very high. This will play an important role in the following empirical analysis. Finally, the absence of the second peak in excess profits is probably due to the shorter 1 week maturity trade not going over year end, and thus not being affected by window dressing activity.

\subsection{A brief comparison to the literature}

Recall from the introduction that most papers examining the stability of the CIP condition assume a trader uses unsecured term money market instruments proxied by Libor rates, often ignoring transaction costs. The introduction to this paper summarized the main issues with such an approach. None-the-less, we reproduce the methodology for the sake of comparison, and call results "Libor profits". We contrast these with this paper's excess returns from unsecured arbitrage, which we label "OIS profits". Both cases explore a long EURUSD spot position.

The two measures are shown in figure 7. The lighter line plots OIS profits and the darker, Libor profits. Generally, the two illustrate a similar pattern. Yet notable differences arise and, importantly, are time varying. These variations stem from Libor-OIS spreads moving unequally across countries. For instance, in periods when Libor-OIS spreads grow more in the target country $j$ relative to the funding country $k$, an upward bias is introduced when measuring CIP arbitrage profits with Libor instead of OIS rates, since profits depend positively on target rates. The reverse is of course also true. Thus, Libor-OIS spreads are a mechanical yet substantive driver of fluctuations in CIP "Libor profits". For this reason, the papers that explain CIP "Libor 
profits" with Libor-OIS spreads are in fact mostly regressing a variable on itself, thereby undermining their claim that risk mostly explains arbitrage deviations.

To close, figure 8 shows the bid-ask spreads related to CIP arbitrage. Average spreads in the forex market, both spot and forward, became more volatile after the start of the crisis in August 2007, but did not increase substantially until the Lehman phase. Only in April 2009 were spreads back to pre-crisis levels. Average OIS spreads instead grew in a step like fashion during the crisis phase, and followed forex spreads in a stunning jump during the Lehman phase. Spreads on funding markets were still at elevated levels in April 2009.

\section{Explaining excess profits from CIP arbi- trage}

\subsection{Risk and liquidity factors}

Why would excess returns from CIP arbitrage have turned positive during the financial crisis? The general answer will come in the flavor of rationing of funds, limiting arbitrage. Higher - perhaps much higher - interest rates alone would not offer a plausible explanation, since the CIP condition should hold for any interest rate differential. We focus the following discussion around two main explanations of market rationing: one emphasizing risk and the other liquidity factors. In each case, explanations can be linked back to a specific player and transaction in figure 1 .

On the risk side, we isolate three causes of excess profits from CIP arbitrage. The first involves the forward transaction between the trader and its forex counterparty. It is therefore shared between both unsecured and secured arbitrage. The risk is that this counterparty defaults during the term of arbitrage; we therefore refer to contract risk. This is as emphasized in Duffie and Huang (1996) and Melvin and Taylor (2009). As a result, the trader would have to close or renew her trading strategy by engaging in a reverse spot transaction, or acquiring a new forward contract. In either case, the trader exposes herself to exchange rate risk.

Second, the trader is exposed to rollover risk, but only in so far as arbitrage is unsecured. Indeed, her unsecured trading strategy involves rolling over overnight money market positions. At any point, though, lender L may stop rolling over the trader's debt, or her management may stop her from renewing her credit to borrower B. This would oblige the trader to terminate her arbitrage strategy early, thereby exposing her to exchange rate risk, as 
above, as well as to the cost of foregone profits. These stem from the maturity structure of overnight interest rate differentials; if it is elevated early in the term of arbitrage and flat thereafter, potential costs diminish, and vice a versa. Acharya, Gale, and Yorulmazer (2009), among others, focus on rollover risk as stemming from investor sentiment, and potentially leading to market freezes. ${ }^{6}$

Third, the trader faces counterparty default risk, as recently emphasized by Taylor and Williams (2009) relative to money market spreads more generally. Again, the risk is specific to the unsecured arbitrage strategy. Specifically, if borrower B were to default, the trader loses the principal of her loan. The risk is usually small, given the overnight maturity, but existent none-the-less, and potentially dissuasive of lending at times of extreme crisis.

On the side of liquidity, we again isolate three potential causes of excess profits from CIP arbitrage. First, there is evidence that banks were under severe pressure to deleverage during the crisis and especially after the Lehman bankruptcy. The impressive extent to which financial institutions deleveraged is documented and discussed in Adrian and Shin (2008b) and McCauley and McGuire (2009), among others. Garleanu and Pedersen (2009) also focus on deleveraging, and suggest a model in which assets with lower margin requirements - with less impact on the balance sheet - can trade at lower prices. ${ }^{7}$ Finally, Cornett, McNutt, Strahan, and Tehranian (2010) suggests that during the crisis the pressure to deleverage was exacerbated by having to honor prior commitments to credit lines, mostly in USD; the paper documents the sharp drop in new loans emanating especially from banks needing to deleverage. Whatever the deeper cause of deleveraging, either strategic or structural, the phenomenon can be captured in our conceptual framework as lender L needing to decrease the size of its balance sheet, thereby reducing

\footnotetext{
${ }^{6}$ Of other papers emphasizing sentiment shocks, one of the founding papers is Shleifer and Vishny (1997) and Pagano (1989), emphasizing self fulfilling prophecies. In the papers that have followed, investor sentiment continues to play a central role, as in Acharya, Gale, and Yorulmazer (2009), as does the availability of information, as in Hombert and Thesmar (2009) and Morris and Shin (2009), where imperfect knowledge of aggregate losses is paramount. On the empirical side, several papers have focussed on measuring liquidity freezes and relevant policy responses. Some of these are Cecchetti and Disyatat (2009), Drehmann and Nikolaou (2009) and Sarkar (2009).

${ }^{7}$ Other papers also emphasize feedback from balance sheets to asset prices, as Acharya and Viswanathan (2007) and Benmelech and Bergman (2009). Other papers emphasize other, although related, factors, such as the structure of financial institutions, as in Diamond and Rajan (2005), He and Krishnamurthy (2008b) and Duffie (2009), that of markets, as in Allen and Gale (2003) and Allen, Carletti, and Gale (2009), or market imperfections as in Mancini Griffoli (2009) and Heider, Hoerova, and Holthausen (2009) which emphasize adverse selection.
} 
both unsecured and secured lending, thereby choking off arbitrage.

The second reason why lender L may have cut back, or cut off, both unsecured and secured loans to arbitrageurs is prudential, as illustrated in part by McGuire and von Peter (2009). By 2008, banks had accumulated substantial dollar assets, funded mostly on a very short term basis on unsecured terms. When the funding markets dried up and when the assets in question became illiquid, banks faced a severe funding strain. Thus, they hoarded liquidity. Doing so had negative externalities, as funding liquidity became all the more scarce and expectations of future liquidity worsened. The situation was exacerbated by signaling dynamics: banks didn't want to be caught by their peers scrambling for liquidity and they knew that posting sufficient liquidity was essential to maintain their credit rating. As a result, banks gave up on lending profits to build up a liquidity pool mostly in USD. These dynamics emphasizing the vicious circle between market and funding liquidity, as well as cross market contagion effects are modeled more explicitly in Brunnermeier and Pedersen (2009), Adrian and Shin (2008a) and Gromb and Vayanos (2009), and eloquently discussed in Brunnermeier (2009) and Pedersen (2009).

Finally, the third reason why arbitrage may have broken down in CIP is specific to the trader engaged in secured arbitrage. Borrowing on secured terms requires capital to cover margins or haircuts. The presumption here is that traders, or hedge funds more specifically, were scrambling for capital especially following the Lehman bankruptcy. On the one hand, funds faced increasing redemptions and on the other, they incurred heavy losses on their portfolios. In a time when raising equity was nearly impossible, available capital became scarce. Due to this constraint, funds were not able to engage in lucrative arbitrage trades. The role played by capital constraints is reviewed with particular clarity in Gromb and Vayanos (2010). It is also at the heart of the models in Acharya, Shin, and Yorulmazer (2009), Brunnermeier and Pedersen (2009), Kondor (2009), He and Krishnamurthy (2008b,a), Liu and Longstaff (2004), Gromb and Vayanos (2002) and Shleifer and Vishny (1997), among others.

\subsection{Variables, specification and methodology}

The earlier section laid out potential explanations for excess profits from CIP arbitrage. These were categorized as mostly involving risk or liquidity factors. The following sections aim to empirically test which explanations seem most correlated to measured excess returns. The general procedure is to regress excess returns from CIP arbitrage on several variables, each of which is intended to capture one of the explanations advanced above. We 
start by listing and justifying these variables, all of which are summarized in Table 1.

On the side of risk, we had highlighted exchange rate risk from having to renegotiate a forward contract, or taping the spot market to terminate arbitrage. We capture this with 1 month forex option implied volatilities. Rollover risk, only present in unsecured arbitrage, also implied early termination of arbitrage. We capture this with the one week to one month OIS differentials in currency $j$ relative to those in currency $k$. This corresponds to potentially lost arbitrage revenue from closing positions after one week instead of the planned one month. And finally we use a CDS index of US financial institutions to track counterparty default risk, also specific to unsecured arbitrage. To these we add a more general measure of risk, drawn from the VIX index for equities.

On the side of liquidity, we had first mentioned the impetus to deleverage. We capture this using the measure of balance sheet size of financial intermediaries developed in Adrian and Shin (2008a). Second, we had emphasized prudential hoarding of USD liquidity, which we track with cash deposits with Federal Reserve Banks in excess of reserve balances. Finally, we had raised the prospects of capital constraints to obtain secured funding. Finding a clean related measure is difficult and, to our knowledge, the literature offers little guidance. None-the-less, we draw inspiration from Coffey, Hrung, Nguyen, and Sarkar (2009) and suggest using a spread between Agency MBS and $\mathrm{GC}$ repo rates. The idea is that as capital becomes scarce, lenders are in a position to extract higher rents in the form of higher repo rates. All repos become specials, in a way. Yet, the presumption is that the effect is stronger on repos with slightly riskier collateral as are MBS relative to GC. To these, we add two more general liquidity measures: First, TED spreads, as in Brunnermeier (2009) and Brunnermeier, Nagel, and Pedersen (2009), implying that liquid capital is withdrawn from markets when it flies to high quality government bonds, and second Libor-OIS spreads. These measures, though, could also represent a heightened perception of risk, both general and of counterparty default. To a certain extent, the same is true of the other liquidity variables. Thus, when testing for liquidity effects, we always also control for risk using the earlier mentioned risk variables. This includes leaving CDS spreads in the regressions for secured arbitrage.

Furthermore, we test for the relevance of liquidity constraints on excess profits by including two variables tracking policy measures to enhance liquidity. If significant and with the appropriate negative sign, these variables would not only signal that policy was effective, but would explain why excess profits from CIP arbitrage were eventually resorbed. The first of these policy variable is the Fed's "reserve bank credits", and the second USD swap 
lines extended by the Fed to other central banks (BOE, BOJ, ECB, SNB). Reserve bank credits include securities held outright, but more importantly repos, term auction credits, other loans, as well as credit extended through the commercial paper funding facility and the money market investor funding facility. While these measures had the goal of improving funding liquidity issues generally, on a variety of markets, swaps were more precisely targeted at solving the issue of dollar funding abroad.

A final two variables are considered, intended to capture market liquidity more generally. These are measures of bid-ask spreads in the funding market (on the two OIS transactions) and forex market (on both the spot and forward transaction). Specifically, in the same spirit as Korajczyk and Sadka (2008), we take the first principal component of the bid-ask spreads of each market's relevant transactions. Two latent liquidity variables arise: one for the forex market and one for the OIS or funding market. ${ }^{8}$

In the end, we estimate the following equation,

$$
z_{t}=\alpha+\nu^{\prime} z_{t-1}+\beta^{\prime} \Theta_{t}+\gamma^{\prime} \Psi_{t}+\delta^{\prime} \Sigma_{t}+\epsilon_{t}
$$

where $\Theta_{t}$ is a matrix including the "market liquidity" variables, $\Psi_{t}$ is a matrix of "funding liquidity" measures, and $\Sigma_{t}$ is a matrix of variables capturing various facets of "risk". Note that all variables are taken in growth rates, as it is primarily the impact of the tightening of funding liquidity on the explosion of excess profits from CIP arbitrage that interests us. Results with variables in levels are discussed in the robustness checks. Estimation is carried out both for the EURUSD times series and for a panel including EURUSD, USDJPY, GBPUSD, and USDCHF. The former is estimated using OLS with Newey-West standard errors, and the latter using Seemingly Unrelated Regression with fixed effects, exchange rate specific constants and autoregressive coefficients.

\subsection{Estimation results}

Regression results are presented in Tables 2, 3 and 4, where the first two tables correspond to 1 month unsecured arbitrage and the last to 1 week

\footnotetext{
${ }^{8}$ The FX latent liquidity variable is defined as the first principle component (FPC) of the bid-ask spreads of the exchange rates (both spot and forward rates) against the USD. The FPC accounts for more than $80 \%$ of the overall liquidity and the loadings are extremely similar across exchange rates. We also tried using a straight average and found, as expected, very similar results. The OIS latent liquidity variable is defined as the FPC that accounts for $60 \%$ of the total volatility and the loadings are very similar across currencies (i.e. between 0.42 and 0.54 ), except for the JPY which has a loading of -0.14 . The exclusion of the latter leaves the results essentially unchanged.
} 
secured arbitrage. Tables 2 and 4 display results for the EURUSD time series, and table 3 for the panel. All tables relay results from trades involving short dollar spot positions; results for the equivalent long dollar spot positions are not shown as they are nearly the same in magnitude and significance, but have opposite signs, since excess returns are nearly mirror images, as discussed earlier. In all tables, several regression specifications are shown, each testing for a different combination of risk and liquidity factors. Finally, for expositional simplicity, we focus the analysis on the results from unsecured arbitrage and comment those from secured arbitrage only in so far as these offer a different or similar picture.

We first focus on the market liquidity variables. These are highly significant across the various specification in the panel case (Table 2). The OIS latent liquidity variable loses significance when taken with the TED spread, reminding us that the latter is also a measure of market liquidity. In the EURUSD time series case, market liquidity variables are less often significant, probably because of the more liquid nature of both forex and related money markets. In all cases the coefficient on forex market liquidity is negative, suggesting higher bid-ask spreads make for lower excess returns. This seems straightforward as spreads reflect transaction costs which run against returns. But the always positive coefficient on the OIS latent liquidity variable suggests another interpretation: that bid-ask spreads are also a measure of funding liquidity. Results suggest that as liquidity becomes depressed on funding markets - or as spreads increase - excess returns grow. This initial result already lays its finger on the importance of liquidity issues.

The next section in the tables focusses precisely on funding liquidity. Here, the general approach is to test each measure of funding liquidity separately given the high collinearity between most variables. The policy variables, though, can be thought of as exogenous; we therefore leave one central bank swap lines - in each regression, except when controlling for the second policy variable, Federal Reserve credits. Note, as mentioned earlier, that in each regression we control for risk premia potentially affecting our liquidity variables by including all risk variables.

TED, Libor-OIS spreads, as well as central bank deposits are all highly significant across both time series and panel regressions. Their positive coefficients indicate that as funding liquidity decreases (an increase in these variables), excess profits from CIP arbitrage increase. That is indeed this paper's central thesis. The Adrian and Shin measure of balance sheet size, though, is not significant. It does gain significance and appears with the expected negative sign in the regressions studied as robustness checks, when all other variables appear in levels.

Interestingly, results suggest the policy responses during the crisis were 
very successful at alleviating the constraint on funding liquidity, and thus contributing to restoring the CIP condition. Coefficients on the reserve credits as well as forex swap lines, in both the time series and panel regressions, are all highly significant. Their negative sign suggests that as these policy measures were implemented, excess CIP profits decreased. Note that both variables are taken with a one week lag, to allow for the transmission of policy. This is when significance is highest, although a two week lag, as well as contemporaneous correlations, are also significant.

Next, we move to the risk variables. The implied volatility (IV) variable is always positive and significant in the EURUSD time series regressions, although the picture is less clear in the more representative panel case. Generally, though, it would seem that exchange rate risk, from having to renegotiate a forward contract or close one's positions early by tapping the spot market, did play some role in propping up excess arbitrage profits.

Results are quite weak for the other risk factors. The CDS and VIX variables are never significant and the interest rate differential is only significant in half the panel regressions, while it is never so in the time series regressions. Thus, counterparty, rollover and more general risk do not seem to have played a role in dissuading arbitrage. This is as expected. We had already mentioned that comparing profits from unsecured and secured arbitrage offered a natural test for the relevance of rollover and counterparty risk. And indeed, since the two arbitrage strategies yield nearly equal results, these risks ought not to have played an important role.

We end with a closer look at regression results from secured arbitrage. The first thing to notice is that results, on the whole, change only very little with respect to the case of unsecured arbitrage, even if the term of arbitrage is different. This is certainly the case for the market and funding liquidity variables, whose importance is thereby emboldened. The CDS and VIX variables also do not change, in that they remain insignificant. And the implied volatility variable loses significance in two of the eight cases, although retains the approximate size of its coefficient. Second, the repo spread variable (Agency MBS to GC repo spreads) is significant, loosely suggesting that there may have been funding liquidity constraints due to finite capital to pledge in exchange.

Generally, then, the above results mostly suggest that CIP deviations can be explained mostly without recourse to risk factors, except for exchange rate risk arising from the default of the forward counterparty. Lack of funding liquidity, and to some extent market liquidity, turn out to be the primary factors explaining why the CIP condition failed in the wake of the Lehman bankruptcy. 


\subsection{Robustness checks}

This section briefly reviews the robustness tests undertaken. For the most part, results are described verbally for the sake of brevity. None-the-less, any specific result is available upon request.

First, we explored the effect of time of day on profits from CIP arbitrage. Results are nearly unchanged with respect to the benchmark $11.00 \mathrm{~h}$ time snap, when using data from the $16.00 \mathrm{~h}$ time snap when US markets are also opened.

Second, we explored the effect of maturity on profits from CIP arbitrage. In general, profits from shorter maturities are less persistent, but higher at their peak. Thus substantial deviations continue to exist and regression results hardly change, as already noted earlier, when considering excess returns from arbitrage over shorter maturities.

Third, we divided the data in sub-samples: a pre-crisis phase, lasting up to August 2007, a crisis phase, between August 2007 and the Lehman bankruptcy in September 2008, and a Lehman phase since then. Liquidity variables in both the $\Theta_{t}$ and $\Psi_{t}$ matrices are not significant during the pre-crisis phase. They then become significant in the crisis phase, and their coefficients grow substantially in the Lehman phase. The risk related variables remain mostly insignificant throughout, as in the main results presented earlier.

Fourth, we also checked to see if results changed when using CDS spreads of European banks instead of US banks. But results are nearly perfectly unchanged. Again, differences in cross country risks are peripheral to our story.

Fifth, results are unchanged to including all explanatory variables in levels. Signs, sizes and significance of coefficients are particularly stable.

Sixth, the same is true when including all variables explored earlier in a single regression. The only exception are TED spreads which lose significance, due to their collinearity with Libor-OIS spreads.

Seventh, results do not change if the risk variables are included separately in the regression.

Eighth, Pastor and Stambaugh (2003) construct a supplementary measure of stock market liquidity which has recently received significant attention. Unfortunately, the fact that this measure is monthly did not allow us to include it directly in our regression. Yet, its correlation with our measures of liquidity in matrix $\Theta_{t}$ is more than $80 \%$.

And finally, in terms of panel estimation, we tried several variants including specific coefficients for the AR term and other estimation methods such as ARCH Maximum Likelihood (Marquardt). Results remain unchanged. 


\section{Conclusion}

This paper focussed on limits to arbitrage as illustrated by covered interest parity, following the Lehman bankruptcy. It described how such arbitrage trades are actually implemented in practice, using either unsecured or secured money market transactions. This paper showed how deviations from CIP arbitrage existed for months after the Lehman bankruptcy, were substantial and persistent, and mostly involved trades with short dollar spot positions. These results were found with data which closely resembles what a trader would have faced at the time of undertaking arbitrage. Data are intra-daily, synchronized across markets and inclusive of transaction costs. Explaining such deviations from arbitrage followed a two step process. The first laid out the hypotheses and the second tested each empirically. Results suggest that it was especially the lack of dollar funding liquidity - due to deleveraging imperatives, prudential hoarding and limited capital to pledge in exchange for liqudity - that limited the extent of arbitrage, and thus failed to balance the CIP condition.

\section{References}

Acharya, V. V., D. M. Gale, and T. Yorulmazer (2009): "Rollover Risk and Market Freezes," CEPR Discussion Papers 7122, C.E.P.R. Discussion Papers.

Acharya, V. V., H. S. Shin, and T. Yorulmazer (2009): "A theory of slow moving capital and contagion," Working Paper, New York University.

Acharya, V. V., and S. Viswanathan (2007): "Leverage, Moral Hazard and Liquidity," Mimeo.

Adrian, T., And H. S. Shin (2008a): "Financial intermediaries, financial stability, and monetary policy," Staff Reports 346, Federal Reserve Bank of New York. (2008b): "Liquidity and leverage," FRBNY Staff Reports no. 328.

Akram, Q. F., D. Rime, and L. SARno (2008): "Arbitrage in the foreign exchange market: turning on the microscope," Journal of International Economics, 76(2), 237 - 253.

Allen, F., E. Carletti, and D. Gale (2009): "Interbank market liquidity and central bank intervention," Journal of Monetary Economics, forthcoming. 
Allen, F., And D. Gale (2003): "Financial fragility, liquidity and asset prices," Wharton Financial Institutions Center working paper no. 01-3\%.

BabA, N., And F. PACKeR (2008): "Interpreting Deviations from Covered Interest Parity during the Financial Market Turmoil of 2007-08," BIS Working Paper no. $26 \%$.

(2009): "From turmoil to crisis: dislocations in the FX swap market before and after the failure of Lehman Brothers," BIS Working Paper no. 285.

Baba, N., F. Packer, and T. Nagano (2008): "The spillover of money market turbulence to FX swap and cross-currency swap markets," BIS Quarterly Review.

Benmelech, E., and N. Bergman (2009): "Credit traps," Harvard University working paper.

Brunnermeier, M. K. (2009): "Deciphering the liquidity and credit crunch 2007-2008," Journal of Economic Perspectives, 23(1), 77-100.

Brunnermeier, M. K., S. Nagel, and L. Pedersen (2009): "Carry trades and currency crashes," NBER Macroeconomics Annual 2008, 23, $313-347$.

Brunnermeier, M. K., And L. H. Pedersen (2009): "Market Liquidity and Funding Liquidity," Review of Financial Studies, 22(6), 2201-2238.

Cecchetti, S. G., and P. Disyatat (2009): "Central bank tools and liquidity shortages," FRBNY Economic Policy Review.

Coffey, N., W. Hrung, H.-L. Nguyen, and A. Sarkar (2009): "The global financial crisis and offshore dollar markets," FRBNY Current Issues in Economics and Finance, 15(6).

Cornett, M. M., J. J. McNutt, P. E. Strahan, and H. Tehranian (2010): "Liquidity risk management and credit supply in the financial crisis," Mimeo.

Diamond, D. W., and R. G. Rajan (2005): "Liquidity Shortages and Banking Crises," Journal of Finance, 60(2), 615-647.

Drehmann, M., and K. Nikolaou (2009): "Funding liquidity risk: definition and measurement," ECB working paper no. 1024. 
Duffie, D. (2009): "The failure mechanics of dealer banks," Rock Center for Corporate Governance, Working Paper No. 59.

Duffie, D., And M. Huang (1996): "Swap rates and credit quality," Journal of Finance, 51, 921-950.

Fong, W.-M., G. Valente, and J. K. W. Fung (2009, forthcoming): "Covered interest arbitrage profits: the role of liquidity and credit risk," Journal of Banking and Finance.

Frenkel, J., And R. M. Levich (1975): "Covered intrest arbitrage: unexploited profits," Journal of Political Economy, 83, 325-338.

(1977): "Transaction costs and interest arbitrage: tranquil versus turbulent periods," Journal of Political Economy, 85, 1209-1226.

Garleanu, N., and L. H. Pedersen (2009): "Margin based asset pricing and deviations from the law of one price," Mimeo, NYU.

Genberg, H., C.-H. Hui, A. Wong, and T.-K. Chung (2009): "The Link between FX Swaps and Currency Strength during the Credit Crisis of 2007-2008," HKMA working paper.

Gromb, D., and D. Vayanos (2002): "Equilibrium and welfare in markets with financially constrained arbitrageurs," Journal of Financial Economics, 66(2-3), 361-407.

(2009): "Financially constrained arbitrage and cross market contagion," INSEAD Working Paper.

(2010): "Limits to arbitrage: the state of the theory," INSEAD Working Paper.

He, Z., And A. Krishnamurthy (2008a): "Intermediary asset pricing," Working Paper, University of Chicago.

- (2008b): "A model of capital and crises," NBER working paper no. 14366 .

Heider, F., M. Hoerova, and C. Holthausen (2009): "Liquidity Hoarding and Interbank Market Spreads: The Role of Counterparty Risk," ECB working paper, forthcoming.

Hombert, J., and D. Thesmar (2009): "Limits of Limits of Arbitrage: Theory and Evidence," CEPR Discussion Papers 7212, C.E.P.R. Discussion Papers. 
Jones, S. (2009): "Deviations from covered interest parity during the credit crisis," NYU Stern Business School working paper.

Keynes, J. M. (1923): A tract on monetary reform. MacMillan and Co., Ltd., London.

Kondor, P. (2009): "Risk in dynamic arbitrage: price effects of convergence trading," Journal of Finance, 64, 638 - 658.

KorAJczyk, R. A., And R. SADKA (2008): "Pricing the commonality across alternative measures of liquidity," Journal of Financial Economics, $87(1), 45-72$.

LiU, J., AND F. LONGSTAFF (2004): "Losing money on arbitrage: optimal dynamic portfolio choice in markets with arbitrage opportunities," Review of Financial Studies.

Mancini Griffoli, T. (2009): "A market for interbank lemons," Mimeo, Swiss National Bank.

MCANDREws, J. (2009): "Segmentation in the US dollar money markets during the financial crisis," FRBNY working paper.

McCauley, R. N., And P. McGuire (2009): "Dollar appreciation in 2008: safe haven, carry trades, dollar shortage and overhedging," BIS Quarterly Review.

McGuire, P., and G. von Peter (2009): "The US dollar shortage in global banking," BIS Quarterly Review.

Melvin, M., And M. P. TAYlor (2009): "The crisis in the foreign exchange market," CEPR Discussion Paper 7472.

Morris, S., ANd H. S. Shin (2009): "Contagious adverse selection," Mimeo, Princeton University.

Pagano, M. (1989): "Trading Volume and Asset Liquidity," The Quarterly Journal of Economics, 104(2), 255-74.

Pastor, L., and R. F. Stambaugh (2003): "Liquidity risk and expected stock returns," Journal of Political Economy, 111(3), 642-685.

Pedersen, L. H. (2009): "When everyone runs for the exit," Mimeo, NYU. 
Rhee, S. G., And R. P. Chang (1992): "Intra-day arbitrage opportunities in foreign exchange and eurocurrency markets," Journal of Finance, 47(1), 363-379.

SARKAR, A. (2009): "Liquidity risk, credit risk and the Federal Reserve's response to the crisis," FRBNY Staff Reports no. 389.

Shleifer, A., and R. W. Vishny (1997): "The Limits of Arbitrage," Journal of Finance, 52(1), 35-55.

Taylor, J. B., and J. C. Williams (2009): "A Black Swan in the Money Market," American Economic Journal: Macroeconomics, 1(1), 58-83.

TAYLOR, M. P. (1989): "Covered Interest Arbitrage and Market Turbulence," Economic Journal, 99(396), 376-91. 


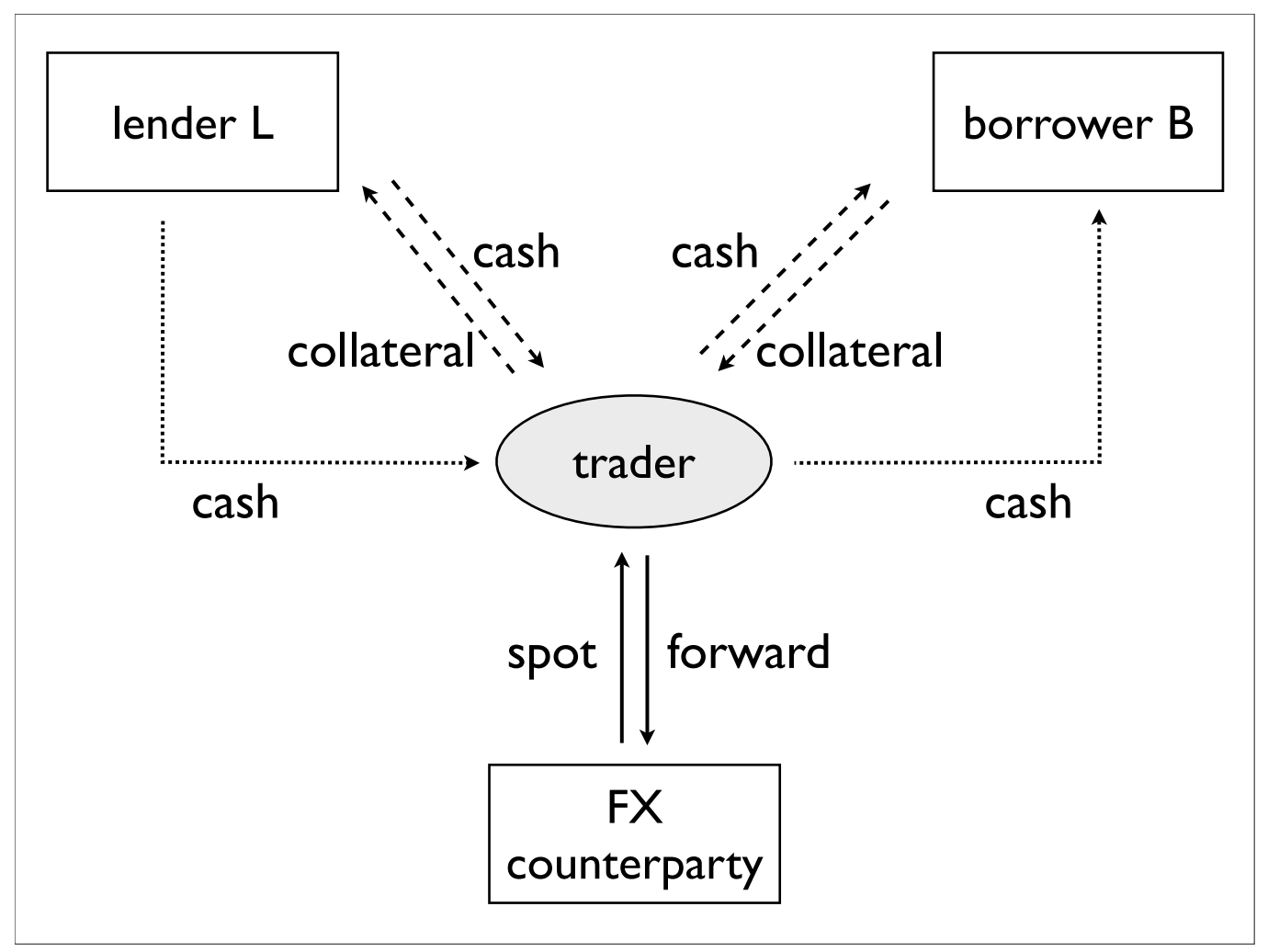

Figure 1: An illustration of CIP arbitrage: the trader can be thought of as either a hedge fund or the prop desk of a large financial institution. Typically, the former borrows and lends on secured terms by exchanging cash against collateral (hashed lines), and the latter does so on unsecured terms (dotted lines). Both are money market transactions. The trader also engages in two forex transactions with appropriate counterparties, one spot and one forward. In all, CIP arbitrage involves four transactions. 


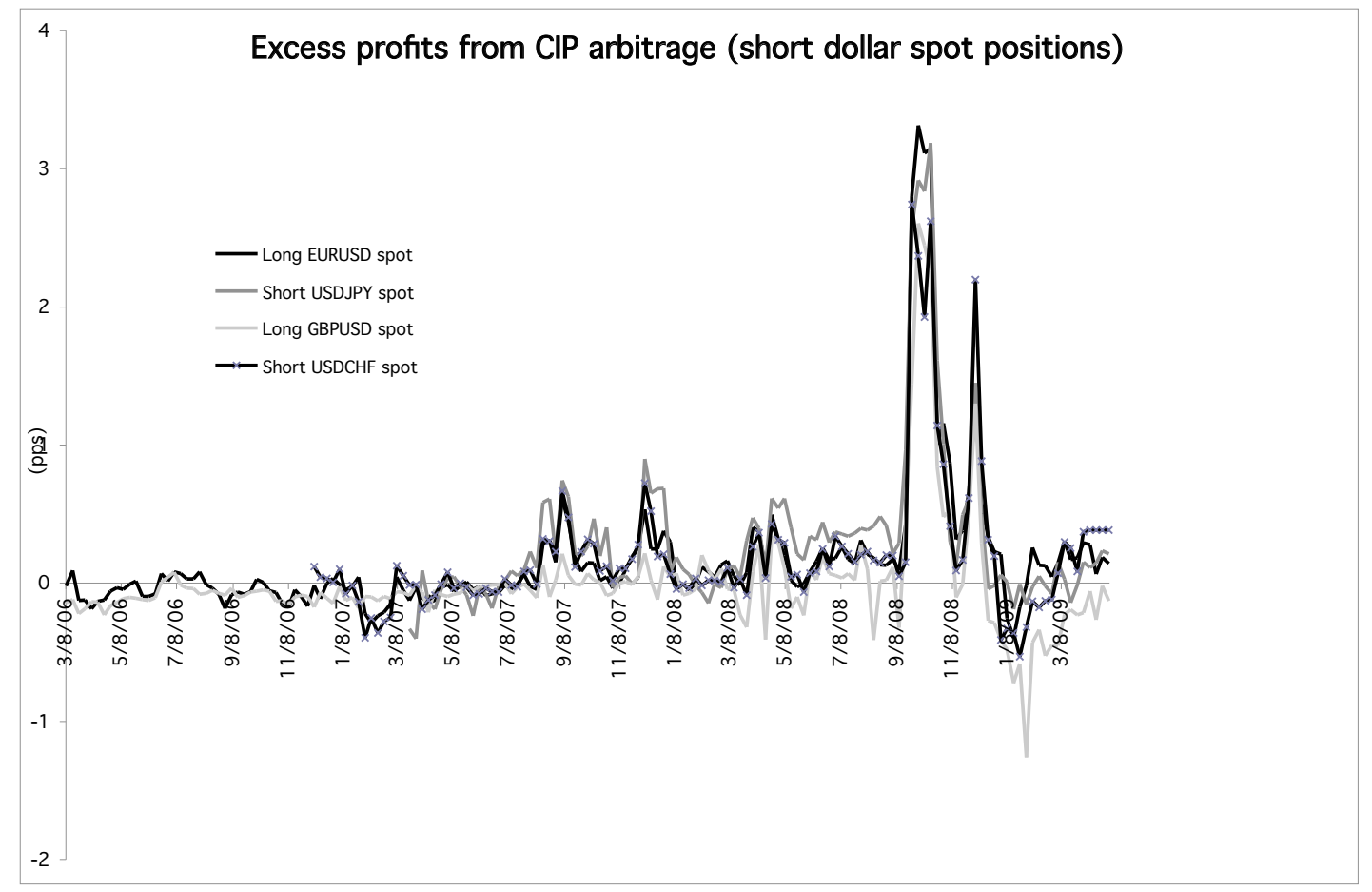

Figure 2: Excess profits from unsecured CIP arbitrage on trades involving a short USD spot position, over a 1 month term. 


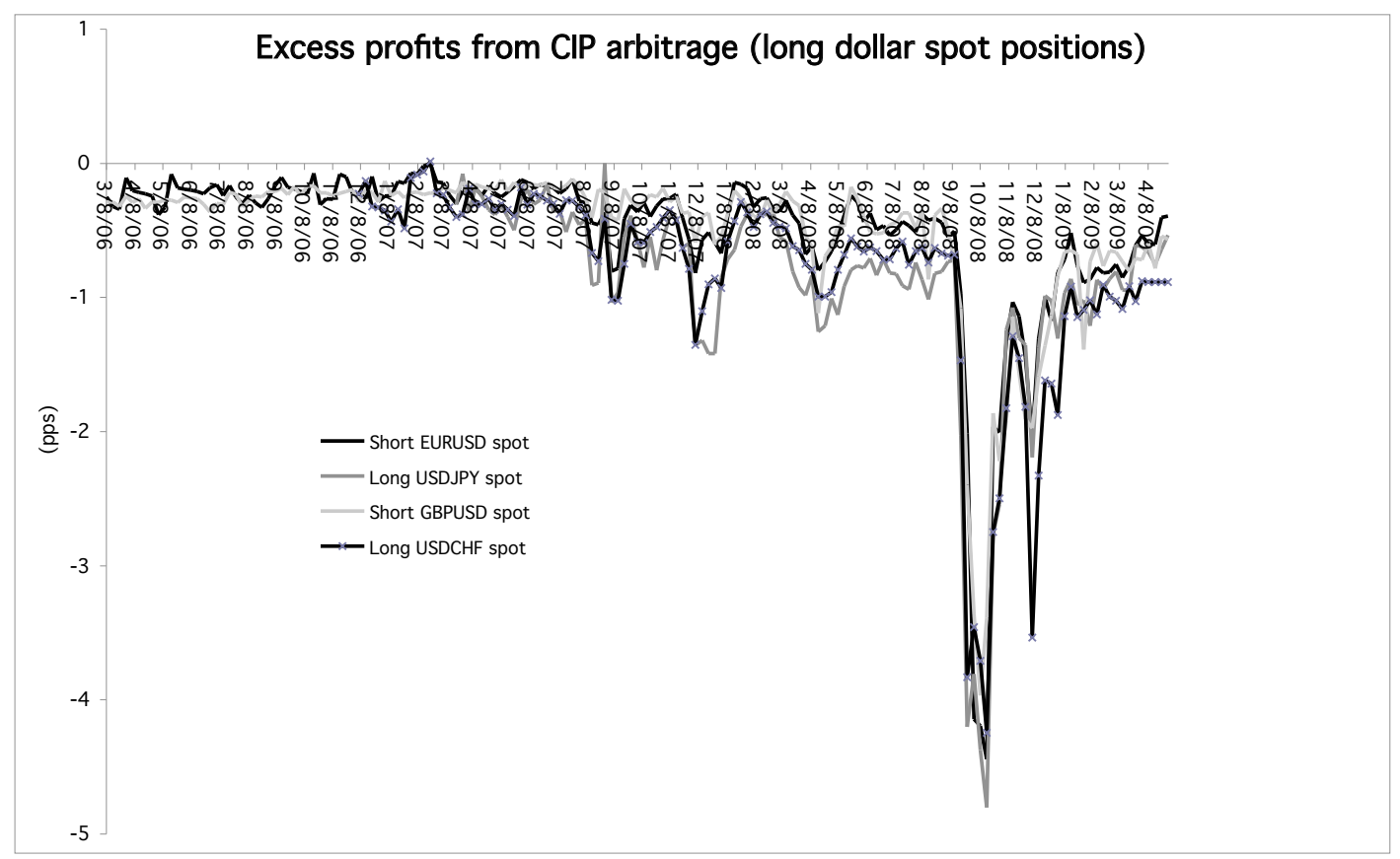

Figure 3: Excess profits from unsecured CIP arbitrage on trades involving a long USD spot position, over a 1 month term. 


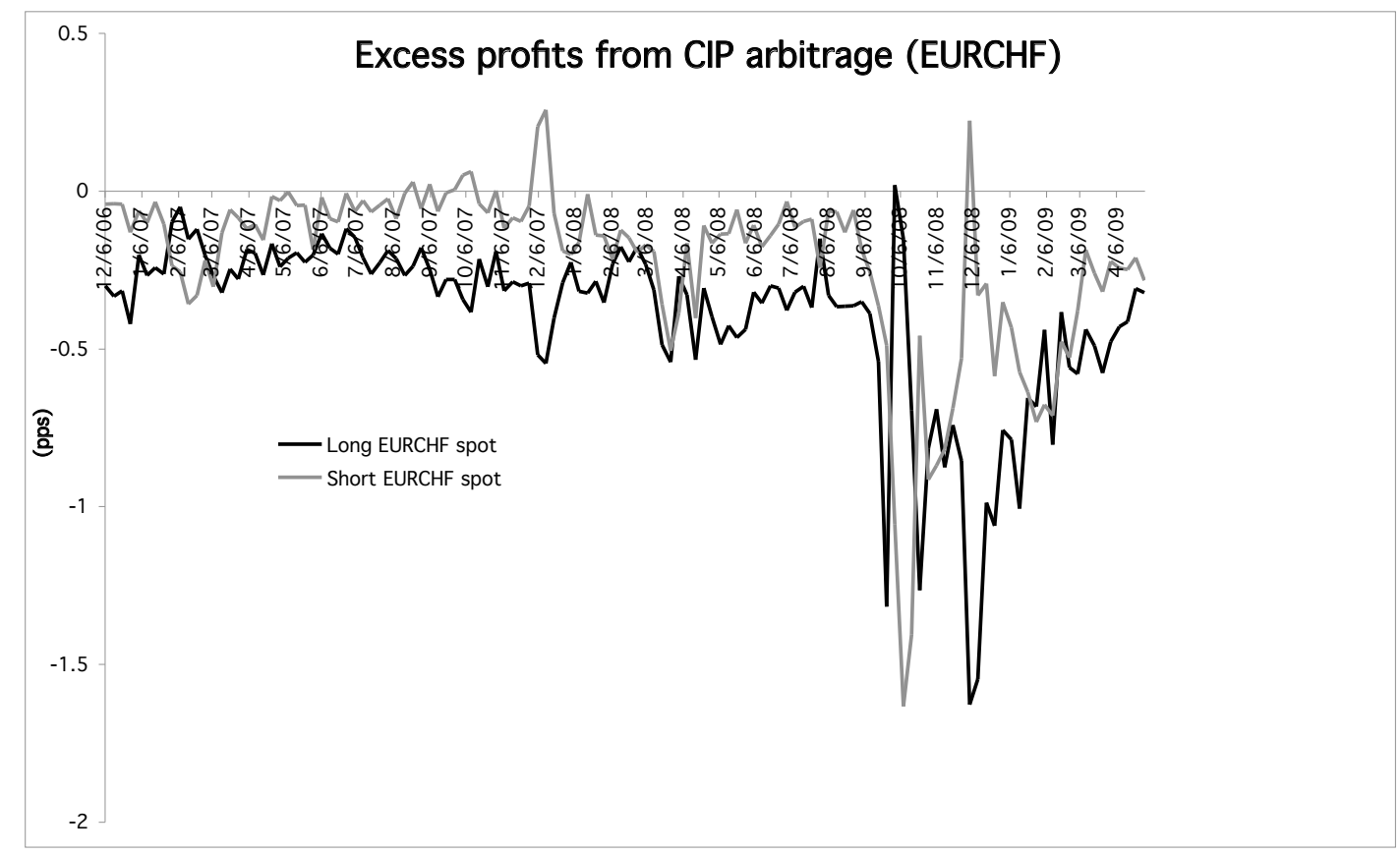

Figure 4: Excess profits from unsecured CIP arbitrage on trades involving both a long and a short EURCHF spot position. 


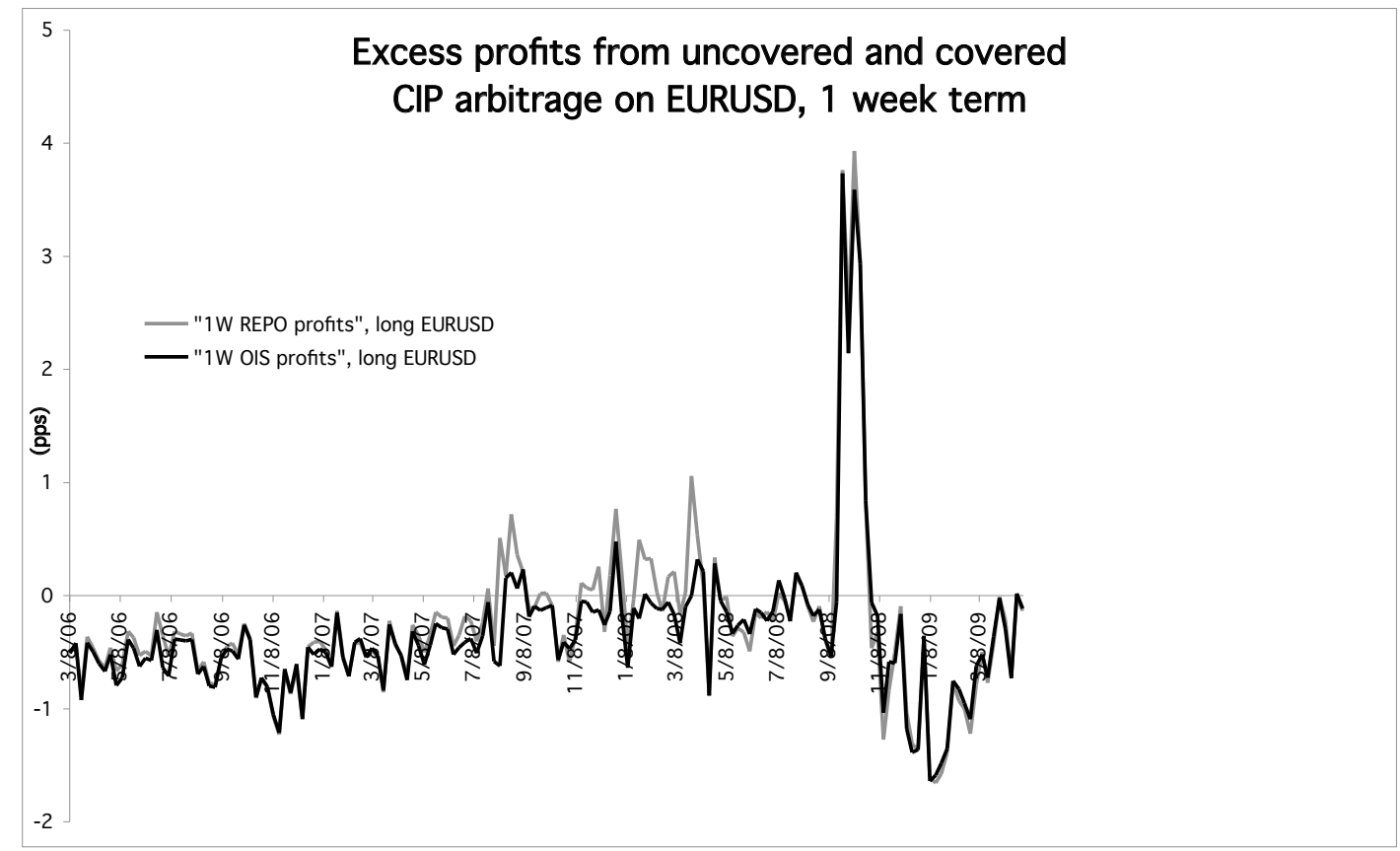

Figure 5: Excess profits from CIP arbitrage on trades involving a short USD spot position, when funding is secured ("repo profits") and unsecured ("OIS profits"), over a 1 week term. 


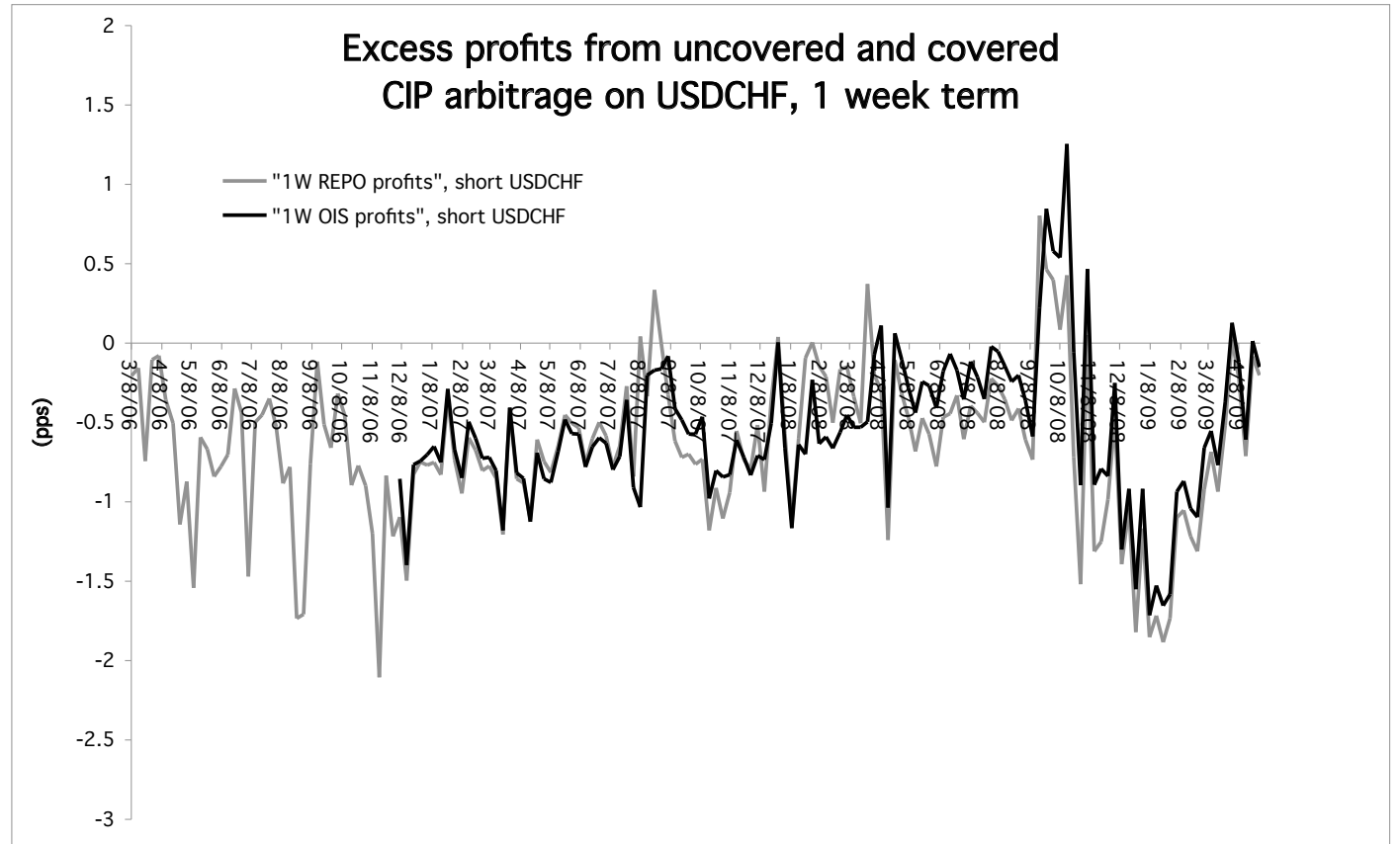

Figure 6: Excess profits from CIP arbitrage on trades involving a short USD spot position, when funding is secured ("repo profits") and unsecured ("OIS profits"), over a 1 week term. 


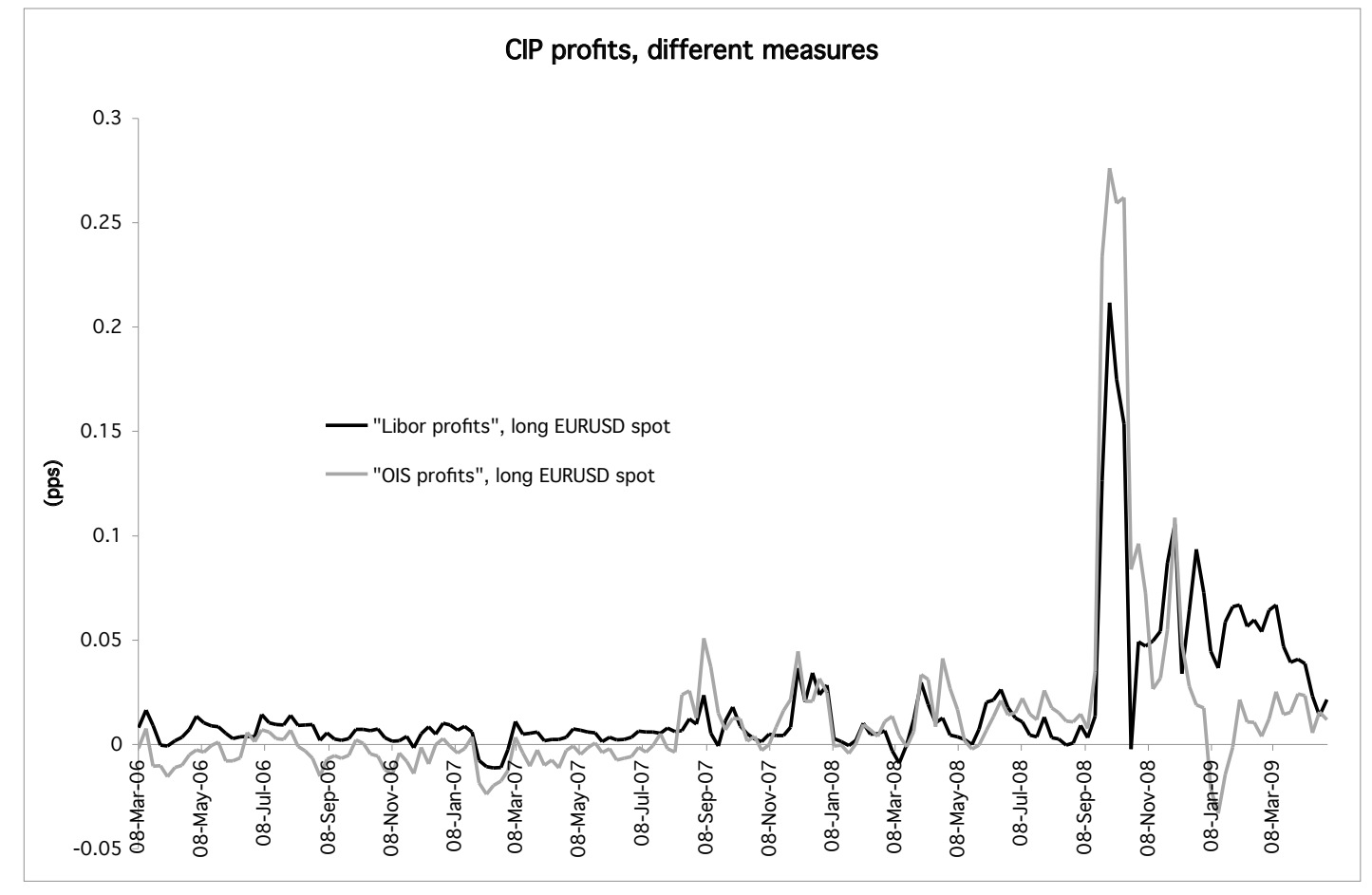

Figure 7: Excess profits in percentage points from CIP arbitrage with 1 month maturity. "Libor profits" are calculated with Libor rates and matching 11am forex quotes, yet without any transaction costs. "OIS profits" are calculated with synchronous OIS and forex rates, including transaction costs; these correspond to the profits shown in earlier figures. 


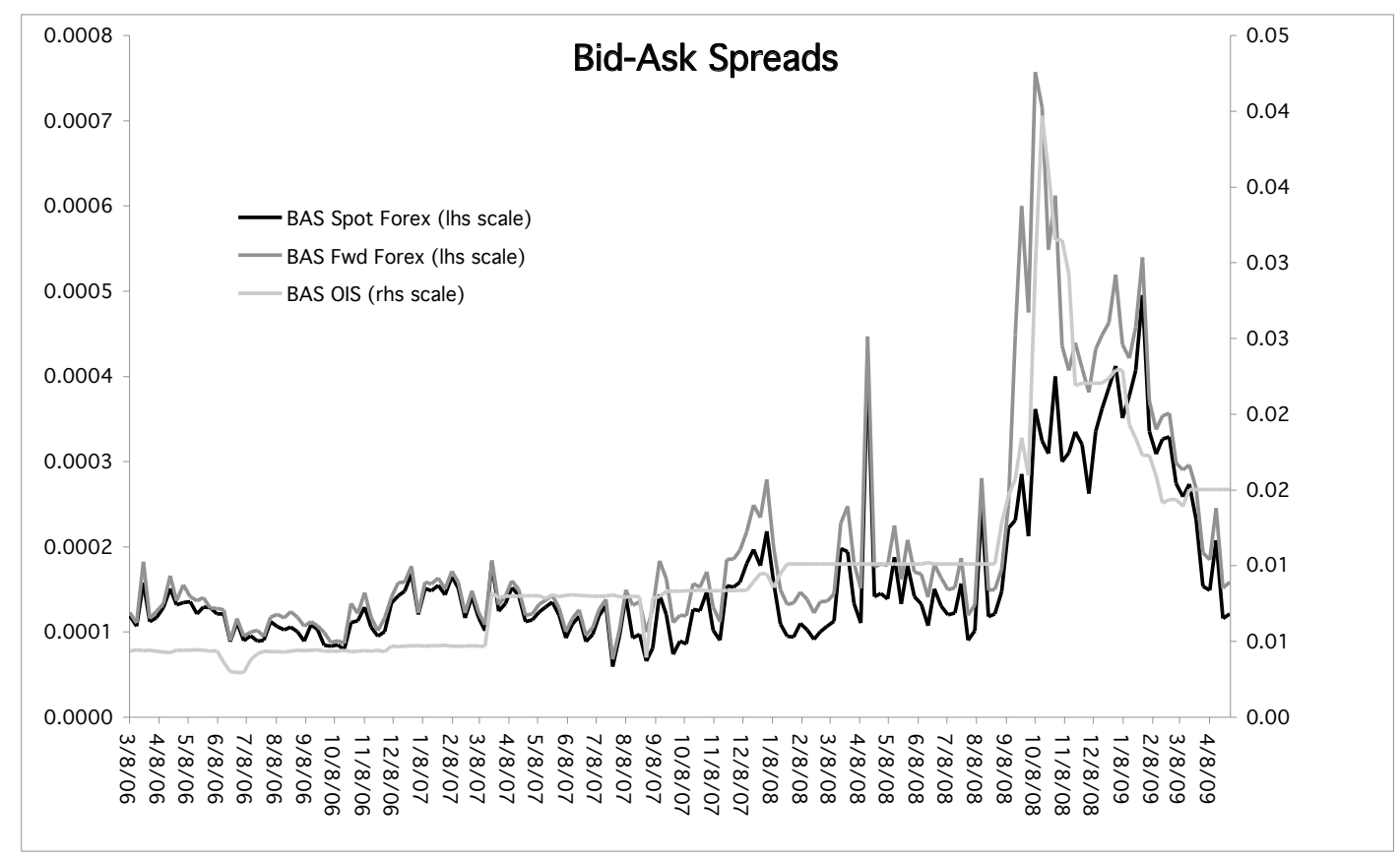

Figure 8: Average bid-ask spreads in the forex spot and forward markets, as well as OIS market. Bid-ask spreads are calculated as $($ Ask-Bid)/C where $C$ is the average midquote. 


\begin{tabular}{lccc} 
& Factor & Unsecured arbitrage proxy & Secured arbitrage proxy \\
\hline Risks & & & \\
\hline & Contract & Implied volatility (IV) & Implied volatility (IV) \\
& Rollover & Interest differential & NA \\
& Counterparty default & CDS & VIX/ CDS \\
\hline Gunding liquidity & & VIX, CDS & \\
\hline & Deleveraging & Balance sheet (CPG) & Balance sheet (CPG) \\
& Prudential hoarding & CB deposits & Repo spreads \\
& Limited capital & NA & CB swaps, \\
& Policy measures & CB swaps, & Reserve credits \\
& General/ controls & Reserve credits & TED, Libor-OIS \\
\hline Market liquidity & & TED, Libor-OIS & OIS \& FX BAS spreads
\end{tabular}

Table 1: Summary of various explanatory factors for excess profits from CIP arbitrage, categorized according to risk, funding liquidity and market liquidity. Each factor is intended to be captured by a corresponding "proxy" or variable. Since some factors are not relevant to both unsecured and secured arbitrage strategies, some proxies are market as not applicable (NA). 


\section{Time series, long EURUSD unsecured CIP arbitrage (1M)}

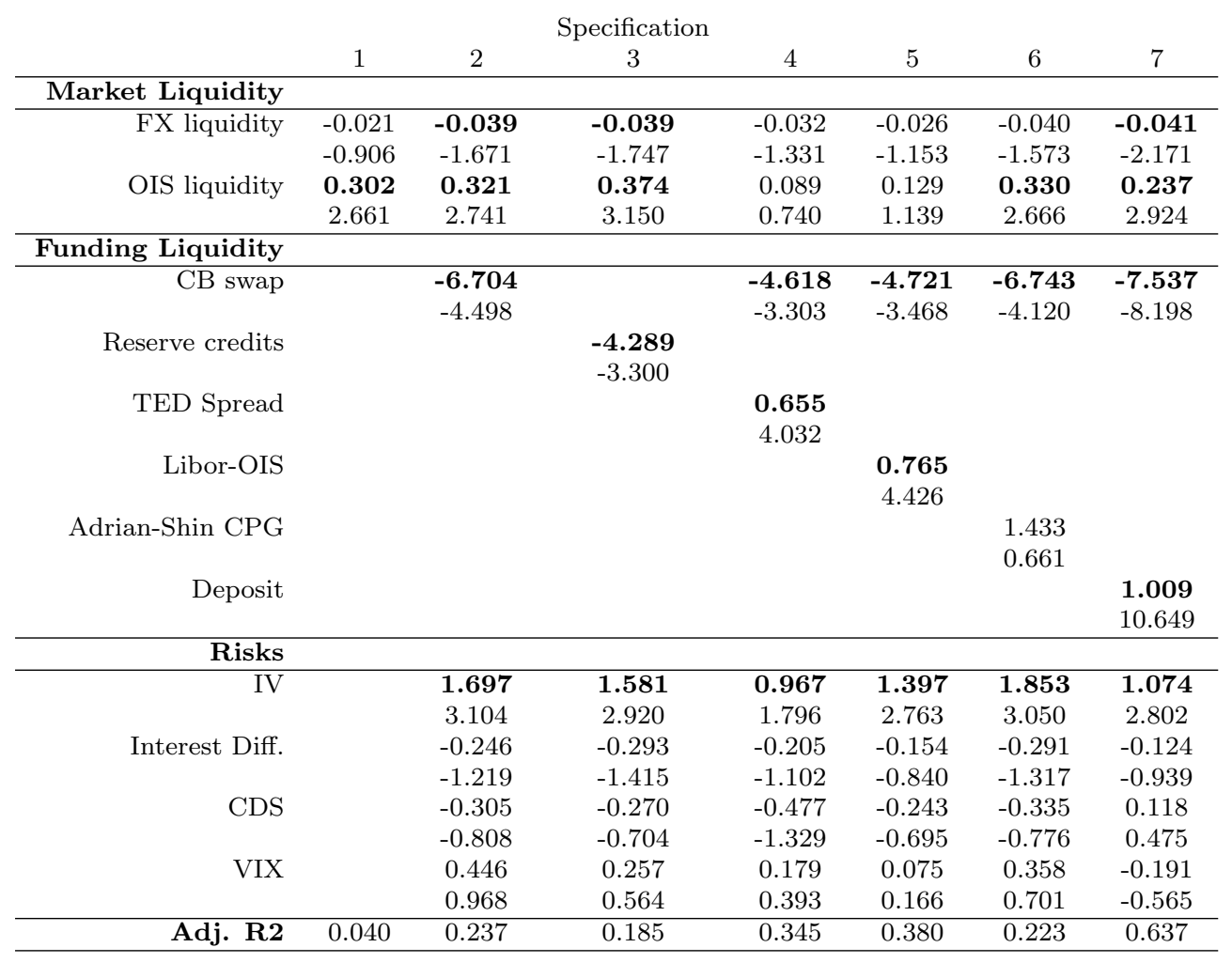

Table II: Time series results for long EURUSD spot positions. For each variable, estimated coefficients appear above corresponding t-statistics. Numbers in bold represent significance at least at the $10 \%$ level. AR(1) coefficients are all significant but not shown to simplify the table. 


\section{Panel, short USD unsecured CIP arbitrage (1M)}

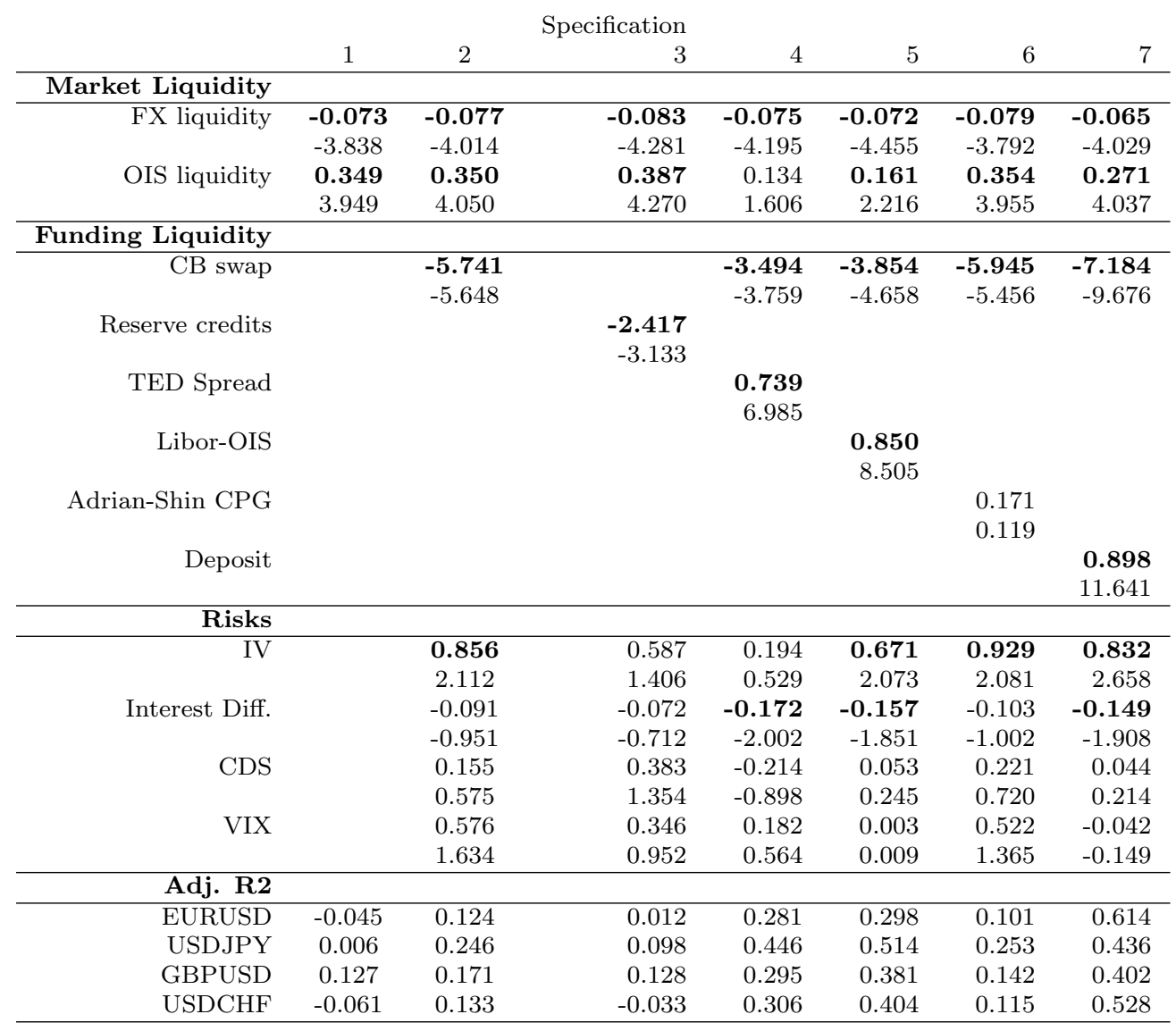

Table III: Panel results for USD group exchange rates, involving short USD spot positions. For each variable, estimated coefficients appear above corresponding t-statistics. Numbers in bold represent significance at least at the $10 \%$ level. AR(1) coefficients are all significant but not shown to simplify the table. 
Time series, long EURUSD secured CIP arbitrage (1W)

\begin{tabular}{|c|c|c|c|c|c|c|c|c|}
\hline & 1 & 2 & 3 & 4 & $\begin{array}{c}\text { Model } \\
5\end{array}$ & 6 & 7 & 8 \\
\hline \multicolumn{9}{|l|}{ Market Liquidity } \\
\hline \multirow{2}{*}{ FX liquidity } & -0.062 & -0.065 & -0.067 & -0.080 & -0.068 & -0.053 & -0.086 & -0.092 \\
\hline & -1.539 & -1.626 & -1.609 & -2.072 & -1.714 & -1.222 & -2.639 & -2.433 \\
\hline \multirow[t]{2}{*}{ OIS liquidity } & 0.746 & 0.776 & 0.854 & 0.491 & 0.658 & 0.765 & 0.738 & 0.483 \\
\hline & 4.166 & 4.568 & 4.536 & 2.899 & 3.857 & 4.369 & 5.673 & 2.976 \\
\hline \multicolumn{9}{|l|}{ Funding Liquidity } \\
\hline \multirow[t]{2}{*}{ CB swap } & & -10.413 & & -8.128 & -9.371 & -9.860 & -12.529 & -7.637 \\
\hline & & -5.448 & & -4.440 & -4.949 & -4.846 & -8.586 & -4.352 \\
\hline Reserve credits & & & $\begin{array}{c}\mathbf{- 4 . 3 7 4} \\
-2.968\end{array}$ & & & & & \\
\hline TED Spread & & & & $\begin{array}{c}\mathbf{0 . 8 1 9} \\
4.055\end{array}$ & & & & \\
\hline Libor-OIS & & & & & $\begin{array}{c}\mathbf{0 . 5 2 9} \\
2.348\end{array}$ & & & \\
\hline Adrian-Shin CPG & & & & & & $\begin{array}{l}2.713 \\
1.060\end{array}$ & & \\
\hline Deposit & & & & & & & $\begin{array}{c}\mathbf{1 . 1 0 9} \\
7.643\end{array}$ & \\
\hline Repo spread & & & & & & & & $\begin{array}{c}\mathbf{0 . 6 1 2} \\
2.685\end{array}$ \\
\hline \multicolumn{9}{|l|}{ Risks } \\
\hline \multirow[t]{2}{*}{ IV } & & 1.521 & 0.803 & 1.013 & 1.515 & 1.611 & 1.379 & 0.887 \\
\hline & & 1.983 & 0.977 & 1.419 & 2.043 & 1.909 & 2.372 & 1.291 \\
\hline \multirow[t]{2}{*}{ CDS } & & 0.099 & 0.264 & -0.003 & 0.166 & 0.239 & 0.284 & -0.114 \\
\hline & & 0.205 & 0.494 & -0.007 & 0.357 & 0.438 & 0.778 & -0.191 \\
\hline \multirow[t]{2}{*}{ VIX } & & 0.379 & 0.011 & -0.167 & -0.022 & 0.087 & -0.300 & -0.138 \\
\hline & & 0.579 & 0.015 & -0.268 & -0.033 & 0.123 & -0.581 & -0.325 \\
\hline Adj. R2 & 0.159 & 0.267 & 0.156 & 0.357 & 0.298 & 0.260 & 0.528 & 0.396 \\
\hline
\end{tabular}

Table IV: Time series results for long EURUSD spot positions. For each variable, estimated coefficients appear above corresponding t-statistics. Numbers in bold represent significance at least at the $10 \%$ level. AR(1) coefficients are all significant but not shown to simplify the table. 


\section{Swiss National Bank Working Papers published since 2004:}

2004-1 Samuel Reynard: Financial Market Participation and the Apparent Instability of Money Demand

2004-2 Urs W. Birchler and Diana Hancock: What Does the Yield on Subordinated Bank Debt Measure?

2005-1 Hasan Bakhshi, Hashmat Khan and Barbara Rudolf: The Phillips curve under state-dependent pricing

2005-2 Andreas M. Fischer: On the Inadequacy of Newswire Reports for Empirical Research on Foreign Exchange Interventions

2006-1 Andreas M. Fischer: Measuring Income Elasticity for Swiss Money Demand: What do the Cantons say about Financial Innovation?

2006-2 Charlotte Christiansen and Angelo Ranaldo: Realized Bond-Stock Correlation: Macroeconomic Announcement Effects

2006-3 Martin Brown and Christian Zehnder: Credit Reporting, Relationship Banking, and Loan Repayment

2006-4 Hansjörg Lehmann and Michael Manz: The Exposure of Swiss Banks to Macroeconomic Shocks - an Empirical Investigation

2006-5 Katrin Assenmacher-Wesche and Stefan Gerlach: Money Growth, Output Gaps and Inflation at Low and High Frequency: Spectral Estimates for Switzerland

2006-6 Marlene Amstad and Andreas M. Fischer: Time-Varying Pass-Through from Import Prices to Consumer Prices: Evidence from an Event Study with Real-Time Data

2006-7 Samuel Reynard: Money and the Great Disinflation

2006-8 Urs W. Birchler and Matteo Facchinetti: Can bank supervisors rely on market data? A critical assessment from a Swiss perspective

2006-9 Petra Gerlach-Kristen: A Two-Pillar Phillips Curve for Switzerland

2006-10 Kevin J. Fox and Mathias Zurlinden: On Understanding Sources of Growth and Output Gaps for Switzerland

2006-11 Angelo Ranaldo: Intraday Market Dynamics Around Public Information Arrivals

2007-1 Andreas M. Fischer, Gulzina Isakova and Ulan Termechikov: Do FX traders in Bishkek have similar perceptions to their London colleagues? Survey evidence of market practitioners' views 
2007-2 Ibrahim Chowdhury and Andreas Schabert: Federal Reserve Policy viewed through a Money Supply Lens

2007-3 Angelo Ranaldo: Segmentation and Time-of-Day Patterns in Foreign Exchange Markets

2007-4 Jürg M. Blum: Why `Basel II’ May Need a Leverage Ratio Restriction

2007-5 Samuel Reynard: Maintaining Low Inflation: Money, Interest Rates, and Policy Stance

2007-6 Rina Rosenblatt-Wisch: Loss Aversion in Aggregate Macroeconomic Time Series

2007-7 Martin Brown, Maria Rueda Maurer, Tamara Pak and Nurlanbek Tynaev: Banking Sector Reform and Interest Rates in Transition Economies: Bank-Level Evidence from Kyrgyzstan

2007-8 Hans-Jürg Büttler: An Orthogonal Polynomial Approach to Estimate the Term Structure of Interest Rates

2007-9 Raphael Auer: The Colonial Origins Of Comparative Development: Comment. A Solution to the Settler Mortality Debate

2007-10 Franziska Bignasca and Enzo Rossi: Applying the Hirose-Kamada filter to Swiss data: Output gap and exchange rate pass-through estimates

2007-11 Angelo Ranaldo and Enzo Rossi: The reaction of asset markets to Swiss National Bank communication

2007-12 Lukas Burkhard and Andreas M. Fischer: Communicating Policy Options at the Zero Bound

2007-13 Katrin Assenmacher-Wesche, Stefan Gerlach, and Toshitaka Sekine: Monetary Factors and Inflation in Japan

2007-14 Jean-Marc Natal and Nicolas Stoffels: Globalization, markups and the natural rate of interest

2007-15 Martin Brown, Tullio Jappelli and Marco Pagano: Information Sharing and Credit: Firm-Level Evidence from Transition Countries

2007-16 Andreas M. Fischer, Matthias Lutz and Manuel Wälti: Who Prices Locally? Survey Evidence of Swiss Exporters

2007-17 Angelo Ranaldo and Paul Söderlind: Safe Haven Currencies 
2008-1 Martin Brown and Christian Zehnder: The Emergence of Information Sharing in Credit Markets

2008-2 Yvan Lengwiler and Carlos Lenz: Intelligible Factors for the Yield Curve

2008-3 Katrin Assenmacher-Wesche and M. Hashem Pesaran: Forecasting the Swiss Economy Using VECX* Models: An Exercise in Forecast Combination Across Models and Observation Windows

2008-4 Maria Clara Rueda Maurer: Foreign bank entry, institutional development and credit access: firm-level evidence from 22 transition countries

2008-5 Marlene Amstad and Andreas M. Fischer: Are Weekly Inflation Forecasts Informative?

2008-6 Raphael Auer and Thomas Chaney: Cost Pass Through in a Competitive Model of Pricing-to-Market

2008-7 Martin Brown, Armin Falk and Ernst Fehr: Competition and Relational Contracts: The Role of Unemployment as a Disciplinary Device

2008-8 Raphael Auer: The Colonial and Geographic Origins of Comparative Development

2008-9 Andreas M. Fischer and Angelo Ranaldo: Does F0MC News Increase Global FX Trading?

2008-10 Charlotte Christiansen and Angelo Ranaldo: Extreme Coexceedances in New EU Member States' Stock Markets

2008-11 Barbara Rudolf and Mathias Zurlinden: Measuring capital stocks and capital services in Switzerland

2008-12 Philip Sauré: How to Use Industrial Policy to Sustain Trade Agreements

2008-13 Thomas Bolli and Mathias Zurlinden: Measuring growth of labour quality and the quality-adjusted unemployment rate in Switzerland

2008-14 Samuel Reynard: What Drives the Swiss Franc?

2008-15 Daniel Kaufmann: Price-Setting Behaviour in Switzerland - Evidence from CPI Micro Data

2008-16 Katrin Assenmacher-Wesche and Stefan Gerlach: Financial Structure and the Impact of Monetary Policy on Asset Prices

2008-17 Ernst Fehr, Martin Brown and Christian Zehnder: On Reputation: A Microfoundation of Contract Enforcement and Price Rigidity 
2008-18 Raphael Auer and Andreas M. Fischer: The Effect of Low-Wage Import Competition on U.S. Inflationary Pressure

2008-19 Christian Beer, Steven Ongena and Marcel Peter: Borrowing in Foreign Currency: Austrian Households as Carry Traders

2009-1 Thomas Bolli and Mathias Zurlinden: Measurement of labor quality growth caused by unobservable characteristics

2009-2 Martin Brown, Steven Ongena and Pinar Yeșin: Foreign Currency Borrowing by Small Firms

2009-3 Matteo Bonato, Massimiliano Caporin and Angelo Ranaldo: Forecasting realized (co)variances with a block structure Wishart autoregressive model

2009-4 Paul Söderlind: Inflation Risk Premia and Survey Evidence on Macroeconomic Uncertainty

2009-5 Christian Hott: Explaining House Price Fluctuations

2009-6 Sarah M. Lein and Eva Köberl: Capacity Utilisation, Constraints and Price Adjustments under the Microscope

2009-7 Philipp Haene and Andy Sturm: Optimal Central Counterparty Risk Management

2009-8 Christian Hott: Banks and Real Estate Prices

2009-9 Terhi Jokipii and Alistair Milne: Bank Capital Buffer and Risk Adjustment Decisions

2009-10 Philip Sauré: Bounded Love of Variety and Patterns of Trade

2009-11 Nicole Allenspach: Banking and Transparency: Is More Information Always Better?

2009-12 Philip Sauré and Hosny Zoabi: Effects of Trade on Female Labor Force Participation

2009-13 Barbara Rudolf and Mathias Zurlinden: Productivity and economic growth in Switzerland 1991-2005

2009-14 Sébastien Kraenzlin and Martin Schlegel: Bidding Behavior in the SNB's Repo Auctions

2009-15 Martin Schlegel and Sébastien Kraenzlin: Demand for Reserves and the Central Bank's Management of Interest Rates

2009-16 Carlos Lenz and Marcel Savioz: Monetary determinants of the Swiss franc 
2010-1 Charlotte Christiansen, Angelo Ranaldo and Paul Söderlind: The Time-Varying Systematic Risk of Carry Trade Strategies

2010-2 Daniel Kaufmann: The Timing of Price Changes and the Role of Heterogeneity

2010-3 Loriano Mancini, Angelo Ranaldo and Jan Wrampelmeyer: Liquidity in the Foreign Exchange Market: Measurement, Commonality, and Risk Premiums

2010-4 Samuel Reynard and Andreas Schabert: Modeling Monetary Policy

2010-5 Pierre Monnin and Terhi Jokipii: The Impact of Banking Sector Stability on the Real Economy

2010-6 Sébastien Kraenzlin and Thomas Nellen: Daytime is money

2010-7 Philip Sauré: Overreporting 0il Reserves

2010-8 Elizabeth Steiner: Estimating a stock-flow model for the Swiss housing market

2010-9 Martin Brown, Steven Ongena, Alexander Popov, and Pinar Yesin: Who Needs Credit and Who Gets Credit in Eastern Europe?

2010-10 Jean-Pierre Danthine and André Kurmann: The Business Cycle Implications of Reciprocity in Labor Relations

2010-11 Thomas Nitschka: Momentum in stock market returns: Implications for risk premia on foreign currencies

2010-12 Petra Gerlach-Kristen and Barbara Rudolf: Macroeconomic and interest rate volatility under alternative monetary operating procedures

2010-13 Raphael Auer: Consumer Heterogeneity and the Impact of Trade Liberalization: How Representative is the Representative Agent Framework?

2010-14 Tommaso Mancini Griffoli and Angelo Ranaldo: Limits to arbitrage during the crisis: funding liquidity constraints and covered interest parity 
Swiss National Bank Working Papers are also available at www.snb.ch, section Publications/Research Subscriptions or individual issues can be ordered at Swiss National Bank, Fraumünsterstrasse 8, CH-8022 Zurich, fax+41 4463181 14, E-mail library@snb.ch 